\title{
Intradaily Variability of Water Quality in a Shallow Tidal Lagoon: Mechanisms and Implications
}

\author{
Lisa V. Lucas ${ }^{1, *}$, Deanna M. Sereno ${ }^{2}$, Jon R. Burau ${ }^{3}$, Tara S. Schraga ${ }^{1}$, Cary B. Lopez ${ }^{4}$, \\ Mark T. Stacey ${ }^{5}$, Konstantin V. Parchevsky ${ }^{6}$, and Vladimir P. Parchevsky ${ }^{7}$ \\ ${ }^{1}$ United States Geological Survey, 345 Middlefield Road, MS \#496, Menlo Park, California 94025 \\ ${ }^{2}$ University of California, Berkeley, 631 Davis Hall \#1710, Berkeley, California 94720-1710 \\ ${ }^{3}$ United States Geological Survey, Placer Hall, 6000 J Street, Sacramento, California 95819-6129 \\ ${ }^{4}$ National Oceanic and Atmospheric Administration, 1305 East-West Highway, Building IV, Silver \\ Spring, Maryland 20910 \\ ${ }^{5}$ University of California, Berkeley, 665 Davis Hall, Berkeley, California 94720-1710 \\ ${ }^{6}$ W. W. Hansen Experimental Physics Laboratory, Stanford University, 455 Via Palou, Stanford, \\ California 94305-4085 \\ 7 Institute of Biology of Southern Seas, Sevastopol, Crimea 99011, Ukraine
}

\begin{abstract}
Although surface water quality and its underlying processes vary over time scales ranging from seconds to decades, they have historically been studied at the lower (weekly to interannual) frequencies. The aim of this study was to investigate intradaily variability of three water quality parameters in a small freshwater tidal lagoon (Mildred Island, California). High frequency time series of specific conductivity, water temperature, and chlorophyll $a$ at two locations within the habitat were analyzed in conjunction with supporting hydrodynamic, meteorological, biological, and spatial mapping data. All three constituents exhibited large amplitude intradaily (e.g., semidiurnal tidal and diurnal) oscillations, and periodicity varied across constituents, space, and time. Like other tidal embayments, this habitat is influenced by several processes with distinct periodicities including physical controls, such as tides, solar radiation, and wind, and biological controls, such as photosynthesis, growth, and grazing. A scaling approach was developed to estimate individual process contributions to the observed variability. Scaling results were generally consistent with observations and together with detailed examination of time series and time derivatives, revealed specific mechanisms underlying the observed periodicities, including interactions between the tidal variability, heating, wind, and biology. The implications for monitoring were illustrated through subsampling of the data set. This exercise demonstrated how quantities needed by scientists and managers (e.g., mean or extreme concentrations) may be misrepresented by low frequency data and how short-duration high frequency measurements can aid in the design and interpretation of temporally coarser sampling programs. The dispersive export of chlorophyll $a$ from the habitat exhibited a fortnightly variability corresponding to the modulation of semidiurnal tidal currents with the diurnal cycle of phytoplankton variability, demonstrating how high frequency interactions can govern long-term trends. Process identification, as through the scaling analysis here, can help us anticipate changes in system behavior and adapt our own interactions with the system.
\end{abstract}

\section{Introduction}

Logistical limitations have historically constrained observations of surface water quality to frequencies ranging from weekly to interannual, but technological developments over the past one to two decades have increasingly allowed for the detection of intradaily (i.e., on the scale of hours) variations in water quality (Taylor and Howes 1994; Hubertz and Cahoon 1999; Kaplan et al. 2003; Lacy et al. 2003; Sanderson and Taylor 2003). This new technology offers a window into the detailed variability of water quality and thereby provides opportunities for increased understanding of long-term trends, im-

\footnotetext{
*Corresponding author; tele: 650/329-4588; fax: 650/3294327; e-mail: llucas@usgs.gov
}

proved design of temporally coarser monitoring programs, and more informed interpretation of low frequency data. This paper describes a study of three transported water quality variables (scalars) measured at high frequency (every $10 \mathrm{~min}$ ) in a small tidal embayment. We characterize periodicities associated with the three scalars, investigate mechanisms causing periodicity to vary between constituents, across short spatial scales, and over time, and explore the implications of high frequency variability.

Identification of intradaily variability is critical in tidal habitats due to the fact that long-term trends and time-averaged quantities can be governed by interactions occurring at higher frequencies (Taylor and Stephens 1993; Lucas et al. 1999a; Vaulot and Marie 1999; Lucas and Cloern 2002). An example is 

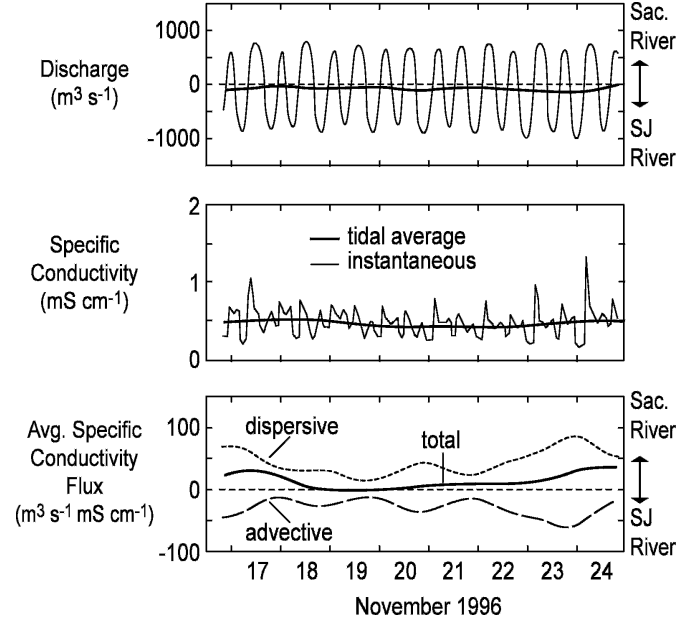

Fig. 1. Measurements of instantaneous and tidally averaged discharge (top panel) and specific conductivity (middle panel), and tidally averaged dispersive, advective, and total specific conductivity flux (bottom panel) for Threemile Slough, California, in November 1996 (Ruhl unpublished data; California Department of Water Resources California Data Exchange Center public communication).

in the calculation of net scalar flux. Many scientists and managers concerned with dissolved substances, particles, or suspended biota in surface waters are interested in constituent flux rates through or between habitats and ecosystems. Advective flux, defined by the product of time-averaged flow rate and time-averaged concentration, is often used as a surrogate for total time-averaged flux because it is relatively simple to calculate and, under certain conditions, may provide a good estimate of the total transport. Other flux components are likely to contribute significantly to total flux in estuarine or other tidal systems (Fischer 1976). An example of these dispersive fluxes is the flux due to the correlation between fluctuations of flow and concentration around their means; observing this flux requires data at high enough frequency to resolve these fluctuations. This particular flux, termed tidal pumping by Fischer et al. (1979), has been demonstrated to be important in estuarine salt transport in a variety of contexts (Stommel and Farmer 1952; Geyer and Nepf 1996; Fram et al. unpublished data). A local example in the Sacramento-San Joaquin Delta involves Threemile Slough, a small tidal channel connecting California's two largest rivers: Sacramento and San Joaquin (Fig. 1; Ruhl unpublished data; California Department of Water Resources California Data Exchange Center public communication; see Fig. 2 for locations). In this case, the net movement of water is from the Sacramento towards the San Joaquin, but the total flux of specific conductivity is in the opposite direction (Fig. 1). The inclusion of fluc- tuations at the tidal time scale (i.e., the dispersive flux) in the calculation of scalar transport resulted in a total flux whose direction was actually the reverse of that obtained only with temporal averages (i.e., the advective flux; total $\approx$ advective + dispersive). This example demonstrates the importance of measuring high frequency variations in transported constituents and flow to accurately characterizing the magnitude and direction of scalar flux in tidal systems. Understanding the genesis of those variations helps us dissect how the fluxes are created and allows us to better anticipate and understand system changes that are ecologically, socially, and geologically significant (Jay et al. 1997).

We analyze high frequency observational data from Mildred Island, a semi-enclosed tidal aquatic habitat in the Sacramento-San Joaquin River Delta, California. We examine three water quality constituents of varying reactivity, specific conductance, water temperature, and chlorophyll $a$, and address the question, how do physical and biological influences (tides, solar radiation, wind, photosynthesis, grazing), which occur at different frequencies, combine to effect high frequency variability in water quality? The mechanisms driving this variability are examined using a scaling approach that combines high frequency water quality data at different locations with hydrodynamic measurements, meteorological data, high resolution spatial maps, and biological rates. In conjunction with the scaling analysis, detailed examination of the original time series and time derivatives reveals mechanisms underlying the variability. We use this data set to demonstrate the implications of high frequency variability for long-term variations in water quality and for monitoring programs, and illustrate the importance of identifying underlying process.

\section{Site Description}

The Sacramento-San Joaquin River Delta (hereafter Delta) is a complex physical system that transitions from a strictly riverine regime at its landward margin to a tidally oscillating interconnected network of channels and open water areas (Fig. 2). Situated at the head of San Francisco Bay and encompassing the confluence of the Sacramento and San Joaquin Rivers, this freshwater ecosystem is subject to numerous physical influences. Operating over time scales ranging from hours to months, these influences are both natural and anthropogenic: mixed diurnal-semidiurnal tides, river and stream inflow, wind stress, solar radiation, density variations due to salinity and temperature gradients, fluctuations in atmospheric pressure, large-scale water removal in the southern Delta via pumping by the federal Central Valley Project and State Water Project, within-Delta agri- 

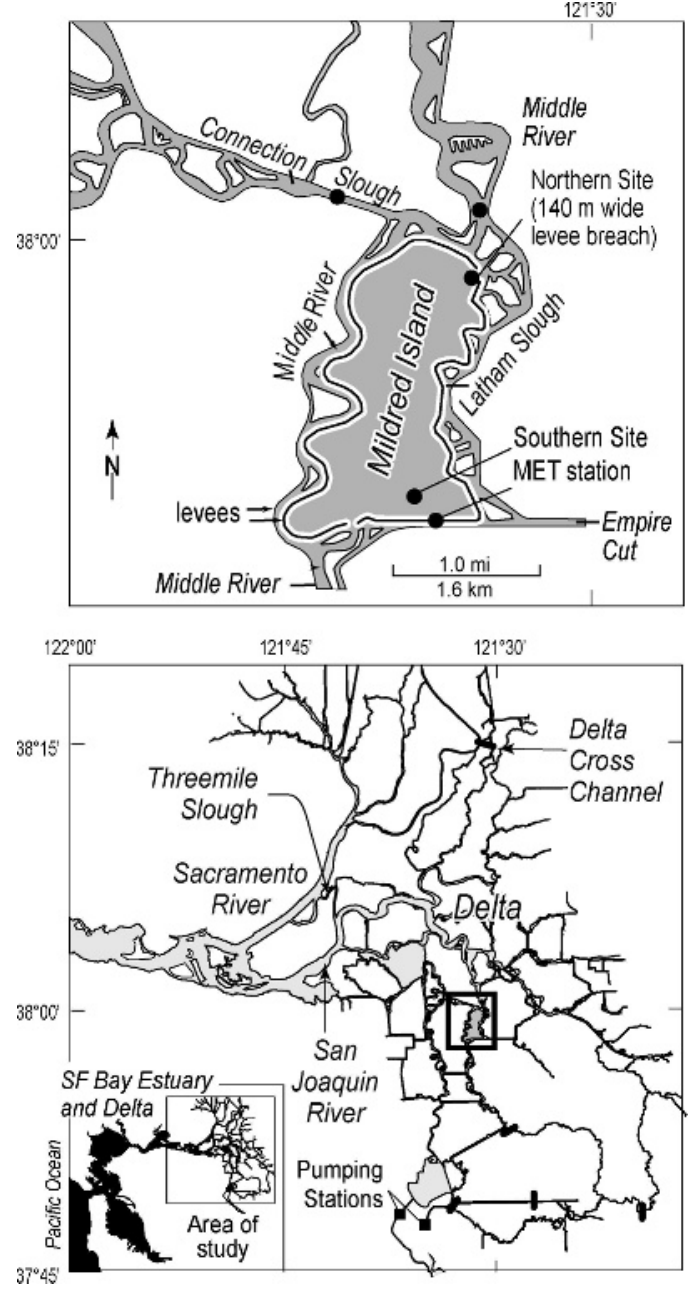

Fig. 2. Map of Mildred Island and the Sacramento-San Joaquin River Delta. Black dots (top panel) represent sites where time series data were collected. Bars (bottom panel) represent gates or barriers.

cultural diversions and returns, and operation of within-Delta gates and barriers.

Our measurements were collected at Mildred Island (MI), a flooded, subsided farm tract in the central Delta (Fig. 2). This open water habitat became flooded in 1983 and has spatially and temporally averaged depth of $5 \mathrm{~m}$, tidal range of $1 \mathrm{~m}$, surface area of $4.1 \mathrm{~km}^{2}$, length of $3 \mathrm{~km}$, average width of approximately $1 \mathrm{~km}$, and maximum tidal currents of order $0.1 \mathrm{~m} \mathrm{~s}^{-1}$ (Monsen et al. 2002). Irregular boundaries create relatively quiescent coves, and breaks in perimeter levees provide local hydrodynamic connections with adjacent deeper channels. A major levee opening in the north (see northern site on Fig. 2) allows tides to propagate into MI from northern Middle River and Connection Slough with peak tidal discharge of $300 \mathrm{~m}^{3} \mathrm{~s}^{-1}$; smaller openings in the south (peak tidal discharge of $8 \mathrm{~m}^{3} \mathrm{~s}^{-1}$ ) and east provide weaker tidal connections with southern Middle River, Empire Cut, and Latham Slough.

Sharp spatial gradients of chlorophyll $a(\operatorname{chl} a)$ in MI were observed in a previous study, and increasing concentrations toward the south were in part attributed to north-south differences in hydrodynamics (Lucas et al. 2002). A numerical model of tidally driven hydrodynamics showed that currents are most intense in northern MI due to the larger, deeper opening there (Monsen et al. 2002). The southeast corner, where chl $a$ concentrations were consistently highest, experienced much weaker currents. The consequent spatial difference in tidal excursion and hydraulic residence time appeared to contribute to higher phytoplankton biomass in the south than in the north (Monsen et al. 2002).

MI is just one example of a shallow water habitat resulting from levee breaches adjacent to subsided lands. Numerous other similar habitats in the Delta are expected to be created either intentionally through a large-scale ecosystem restoration program (CALFED 2000; Lucas et al. 2002; Jacobs et al. 2003; California Bay-Delta Authority 2004) or unintentionally through unplanned and unanticipated levee failures (Mount and Twiss 2005). This study of variability and process interaction within a flooded farm tract enhances our understanding of how future Delta habitats, whether intended or unintended, may function. MI is similar to other shallow embayments subjected to tides, wind, and heating, and so the variability, processes, implications, and techniques discussed here are relevant to countless other systems (e.g., coastal lagoons, marshes, deltas) where these forcings are at play. The relatively small size and simple geometry of MI permitted spatially intense measurements throughout the habitat and outside its boundaries, providing a tractable venue for detailed study of process interactions relevant to other tidal environments.

\section{Methods}

\section{Time Series Measurements}

Time series of chl a fluorescence, specific conductance (SC), water temperature (T), and current velocity $(\overrightarrow{\mathrm{U}})$ were obtained at fixed sampling sites at MI during summer and fall 2001. Moored instruments were deployed on August 23, 2001. While SC, T, and $\overrightarrow{\mathrm{U}}$ were measured at 8 stations in MI and its adjacent channels, fluorescence was measured at only two of those stations (northern and southern sites, Fig. 2). Measurements at these two stations are the focus of this paper. Upper and lower water column measurements of SC, T, and chl $a$ were obtained at the northern and southern sites with twin instrument 


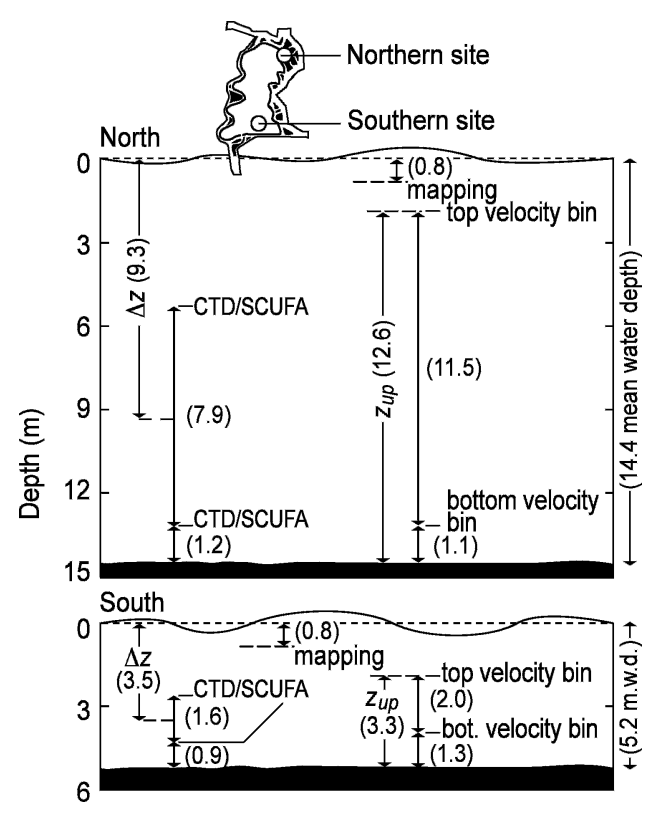

Fig. 3. Elevation view schematic of sampling setup for north and south stations. Mapping denotes depth of shipboard spatial mapping measurements.

packages at both stations. All instruments were deployed at fixed heights relative to the bottom (see Fig. 3 for sampling setup).

Submersible fluorometers (SCUFA, Turner Designs, Inc.) measured and logged chl $a$ fluorescence every $10 \mathrm{~min}$. Discrete chl $a$ water samples were collected for calibration approximately weekly for $1 \mathrm{mo}$; thereafter, biofouling caused the fluorescence data to be unreliable. Water samples were stored in the dark on ice and filtered onto GF/F filters (Gelman Sciences) as soon as possible, following standard methods for chl $a$ (Parsons et al. 1984). Filters were immediately frozen and kept at $-80^{\circ} \mathrm{C}$ until later extraction and analysis (Parsons et al. 1984). Discrete chl $a$ was regressed linearly against fluorometer voltage $\left(\mathrm{r}^{2}=0.84\right.$ for the northern site; $r^{2}=0.91$ for the southern site); these linear equations were used to convert time series of fluorescence to chl $a$. Seabird CTDs measured and logged SC and T every $10 \mathrm{~min}$. Acoustic Doppler Current Profilers (ADCP, SonTek/YSI, Inc. and RD Instruments) obtained velocity profiles every $10 \mathrm{~min}$ at $0.5-\mathrm{m}$ bins throughout the water column. Velocity in the top bin is shown. SC, T, and $\vec{U}$ series were obtained for approximately 3 mo.

A meteorological station was installed on September 3, 2001 to measure air temperature, wind speed, and wind direction. Surface photosynthetically active radiation (PAR) was taken to be $45 \%$ of total radiation (Miyamoto et al. 1997) measured at Brentwood, California, by California Irrigation Management Information System (CIMIS public communication). CIMIS solar radiation and air vapor pressure were used in atmospheric heat flux $(\Delta \mathrm{H})$ calculations, which followed the approach of Thomann and Mueller (1987). Saturated vapor pressure was estimated as suggested by Shanahan (1985).

\section{SPATIAL MAPPING}

Spatial mapping of water quality was accomplished concurrently aboard the $\mathrm{R} / \mathrm{V}$ Turning Tide (inside MI) and R/V San Carlos (in adjacent channels) on September 5-6, 2001. Sampling circuits were centered temporally around 5 consecutive slack tides. Along the circuits, ambient water was pumped continuously from approximately $1 \mathrm{~m}$ depth and delivered to onboard instruments for measurement of chl $a$ fluorescence (Turner Designs 10-AU fluorometer), SC (SeaBird Electronics SBE 4 conductivity sensor), and $\mathrm{T}$ (SeaBird Electronics SBE 3 temperature sensor). Measurements and GPS location were obtained and recorded every $5 \mathrm{~s}$. Discrete water samples for determining concentrations of chl $a$ for fluorometer calibration were collected and analyzed using the same procedure as for the SCUFAs $\left(\mathrm{r}^{2}=0.98\right.$ for $\mathrm{R} / \mathrm{V}$ Turning Tide; $\mathrm{r}^{2}=0.88$ for R/V San Carlos).

\section{Data ANALysis}

Current velocities at fixed stations were rotated into a coordinate system aligned with their respective principal directions. Assignment of principal directions was based on direction histograms and local geometry. At the northern site, a location that is strongly tidally forced, the principal (streamwise) direction of $100^{\circ}$ (relative to true North) was chosen, corresponding to the dominant ebb direction (i.e., positive streamwise velocity represents ebb tide or flow out of MI). For the southern site, the streamwise direction $\left(203^{\circ}\right)$ represents the predominant flow orientation. The transverse direction (normal to the streamwise direction and in this case $293^{\circ}$ ) represents a superimposed oscillatory flow with positive velocity signifying flow out of the southeast corner toward the southern instrument site. Depth-averaged velocity $(\overline{\overrightarrow{\mathrm{U}}})$ measured by the northern fixed ADCP (average of all vertical bins) had a good relationship with mean cross-sectional velocity $\left(\overrightarrow{\mathrm{U}}_{\mathrm{a}}\right)$ determined with boat-mounted ADCP measurements over the cross section and over a full tide cycle $\left(\overrightarrow{\mathrm{U}}_{\mathrm{a}}=-0.3106 \times \overline{\overrightarrow{\mathrm{U}^{2}}}+0.9053 \times \overline{\overrightarrow{\mathrm{U}}}-0.01891, \mathrm{r}^{2}\right.$ $=0.973$; Ruhl and Simpson 2005; Cuetara et al. unpublished data). A similar relationship in southern MI was not attempted because that region was unconfined and no well-defined cross section existed. 
Power spectra and autocorrelations were calculated to identify the dominant periods in the time series. Values of variance associated with individual peaks in the power spectra were calculated as the integral of energy density over the peak (in frequency space) using trapezoidal integration. Autocorrelations were calculated for 14 consecutive 3-d subseries with start times spaced $1 \mathrm{~d}$ apart. Contour maps of SC, T, and chl $a$ were interpolated from interior mapping circuits. Interpolation onto a 50-m grid was performed by Kriging with a linear variogram model and slope of 1.0. Time derivatives were calculated using Tikhonov regularization, following Parchevsky (2000) and Parchevsky and Parchevsky (2001a,b). For the calculation of dispersive flux of chl $a$, velocities were converted to total discharge (water mass flux, $\mathrm{Q}, \mathrm{m}^{3} \mathrm{~s}^{-1}$ ) through the flow cross section using the rating process of Ruhl and Simpson (2005). Depth-averaged chl $a(\overline{\operatorname{chl} a})$ was estimated as the average of values obtained by upper and lower sensors. Dispersive flux was calculated as $\left\langle Q^{\prime} \overline{\operatorname{chl} a^{\prime}}>\right.$, where ' represents high frequency departures from the tidal average and $\langle>$ represents the tidal average (Fischer et al. 1979). Averaging was performed with a digital filter (Walters and Heston 1982).

\section{SCALING ANALYSIS}

The evolution of a scalar constituent of concentration $\mathrm{C}$ may be described by the following equation:

$$
\begin{aligned}
\underbrace{\frac{\partial \mathrm{C}}{\partial \mathrm{t}}}_{(\mathrm{I})}= & \underbrace{-\mathrm{u} \frac{\partial \mathrm{C}}{\partial \mathrm{x}}-\mathrm{v} \frac{\partial \mathrm{C}}{\partial \mathrm{y}}}_{(\mathrm{II})} \\
& +\underbrace{\frac{\partial}{\partial \mathrm{z}} \mathbf{K}_{\mathrm{z}} \frac{\partial \mathrm{C}}{\partial \mathrm{z}}}_{(\mathrm{III})} \pm \underbrace{\gamma \mathrm{C}}_{(\mathrm{IV})}+\underbrace{\dot{\mathrm{C}}}_{(\mathrm{V})}
\end{aligned}
$$

where (I) is the time derivative, (II) are the horizontal advection terms, (III) is vertical turbulent mixing, (IV) is first order growth or loss, and $(\mathrm{V})$ is an additional source term. $\mathrm{x}$ and y represent horizontal distance in the streamwise and transverse directions, respectively; $\mathrm{z}$ is distance in the vertical dimension; $\mathrm{u}$ and $\mathrm{v}$ are streamwise and transverse current velocity, respectively; $\mathrm{K}_{\mathrm{z}}$ is the vertical turbulent mixing coefficient; and $\gamma$ is specific growth or loss rate. Equation 1 neglects vertical advection and horizontal mixing.

To illuminate the most important processes underlying intradaily variability of $\mathrm{C}$, we can estimate the contribution of each process to the observed periodic variability. Here we scale the magnitude of oscillation, $\Delta \mathrm{C}$ (trough to peak), associated with horizontal advection, vertical tur- bulent mixing, vertical heat flux between the atmosphere and water, evaporation, net phytoplankton growth, and zooplankton grazing. To scale the $\Delta \mathrm{C}$ attributable to a periodic forcing mechanism, two key quantities are needed: the amplitude of the process rate and the period of the forcing. The rate (e.g., velocity, heat flux) determines the amount of change in $\mathrm{C}$ occurring over some span of time $\Delta \mathrm{t}$, while the period determines how long that process acts to create a fluctuation in concentration.

To illustrate this calculation, suppose that one of the terms on the right side of Eq. 1 can be represented as a simple cosine function such that $\partial \mathrm{C} / \partial \mathrm{t}=\mathrm{A} \cos (2 \pi \mathrm{t} / \tau)$, where $\mathrm{A}$ is the amplitude of the process rate and $\tau$ is the period of the forcing. Integration of this equation to define the change in concentration gives:

$$
\Delta \mathrm{C}=\mathrm{C}(\mathrm{t})-\mathrm{Co}=(\mathrm{A} \tau / 2 \pi) \sin (2 \pi \mathrm{t} / \tau)
$$

such that the magnitude of the water quality fluctuation $(\Delta \mathrm{C})$ depends on both the (amplitude of) the process rate and the period of the forcing mechanism. Our analysis of $\Delta \mathrm{C}$ (where $\mathrm{C}$ is $\mathrm{T}, \mathrm{SC}$, or chl a) employs a similar integration, with each process term in Eq. 1 represented by a function containing a sine or cosine. Since we are interested in hourly scale oscillations of $\Delta \mathrm{C}$, we neglect the contribution of any nonzero mean superimposed on the oscillating part of a process. We treat terms II-V in Eq. 1 separately, assuming only one component in each term is periodic. To derive the oscillation magnitude associated with streamwise horizontal advection $\left(\Delta \mathrm{C}_{\mathrm{adv}-\mathrm{x}}\right)$, we assume the first two terms approximately balance, treating advection in the $\mathrm{x}$-direction separately from advection in the $\mathrm{y}$ direction. We next assume that $u$ is the primary oscillating component of $\Delta \mathrm{C}_{\mathrm{adv}-\mathrm{x}}$, let $\mathrm{u}=\hat{\mathrm{u}} \sin (2 \pi \mathrm{t} /$ $\tau)$, and take the streamwise scalar gradient $\partial \mathrm{C} / \partial \mathbf{x}$ as a constant ( $\hat{u}$ is the amplitude of the oscillating streamwise velocity). The result of the integration is presented in Table 1 (Eq. A), and the same analysis applied to the transverse velocity results in Eq. B.

Two vertical mixing processes were examined for their ability to cause oscillations in water quality: mixing generated by current shear $\left(\Delta \mathrm{C}_{\text {mix-cs }}\right)$ and that induced by turbulent kinetic energy input from the wind $\left(\Delta \mathrm{C}_{\text {mix-wind }}\right)$. The general form of $\Delta \mathrm{C}_{\text {mix }}$ (Table 1, Eq. C) derives from an assumed balance between terms I and III in Eq. 1. This relationship was applied separately for the two sources of mixing. The turbulent mixing coefficient, $\mathrm{K}_{\mathrm{z}}$, is proportional to shear velocity $\left(\mathrm{u}_{* \mathrm{cs}}\right.$ for current shear, $\mathrm{u}_{* \text { wind }}$ for wind), which is assumed to be the primary oscillating component of $\Delta \mathrm{C}_{\mathrm{mix}}$. 
TABLE 1. Scaling expressions derived for estimating scalar oscillation magnitudes $(\Delta \mathrm{C})$ associated with various periodic processes. Expressions for $\Delta \mathrm{C}$ apply to all scalars; expressions for $\Delta \mathrm{SC}, \Delta \mathrm{T}$, or $\Delta \mathrm{Chl}$ apply only to specific conductance, water temperature, and chlorophyll $a$, respectively. Parameter definitions and values used in calculations are shown in Table 2. Derivation and calculation details are in Appendix.

\begin{tabular}{|c|c|c|}
\hline & Scaling Expression & Process Driving Scalar Oscillation \\
\hline Equation A & $\Delta \mathrm{C}_{\mathrm{adv}-\mathrm{x}} \sim \hat{\mathrm{u}} \frac{\tau}{\pi} \frac{\partial \mathrm{C}}{\partial \mathrm{x}}$ & Streamwise advection \\
\hline Equation B & $\Delta \mathrm{C}_{\mathrm{adv}-\mathrm{y}} \sim \hat{\mathrm{v}} \frac{\tau}{\pi} \frac{\partial \mathrm{C}}{\partial \mathrm{y}}$ & Transverse advection \\
\hline Equation $\mathrm{C}$ & $\Delta \mathrm{C}_{\text {mix }} \sim \hat{\mathrm{u}}_{*} \frac{\tau}{\pi}\left(\frac{0.067 \overline{\mathrm{h}}\left(1+3.33 \mathrm{Ri}_{\mathrm{g}}\right)^{-3 / 2}}{\Delta \mathrm{z}}\right) \frac{\partial \mathrm{C}}{\partial \mathrm{z}}$ & Vertical turbulent mixing \\
\hline Equation D & $\Delta \mathrm{T}_{\text {heat }} \sim \frac{\Delta \hat{\mathrm{H}}}{\rho_{\mathrm{o}} \mathrm{c}_{\mathrm{p}} \overline{\mathrm{h}}}\left(\frac{\tau}{\pi}\right)$ & Atmospheric heating \\
\hline Equation $\mathrm{E}$ & $\Delta \mathrm{SC}_{\text {evap }} \sim \frac{\mathrm{SC}_{\mathrm{o}}}{\mathrm{h}_{\mathrm{o}}}\left(\hat{\mathrm{E}}_{\mathrm{v}} \frac{\tau}{\pi}\right)$ & Evaporation \\
\hline Equation $\mathrm{F}$ & $\Delta \operatorname{Chl}_{\text {growth }} \sim \operatorname{Chl}_{\mathrm{o}}\left[\exp \left(\frac{\tau}{\pi} \hat{\mu}\right)-1\right]$ & Phytoplankton growth \\
\hline Equation $\mathrm{G}$ & $\Delta \mathrm{Chl}_{\mathrm{zp}} \sim \mathrm{Chl}_{\mathrm{o}}\left[\exp \left(\frac{\tau}{\pi} \hat{\mu}_{\mathrm{zp}}\right)-1\right]$ & Zooplankton grazing \\
\hline
\end{tabular}

Our scaling estimate for $\Delta \mathrm{T}_{\text {heat }}$, the temperature fluctuation due to atmospheric heat flux, is based on an assumed balance between the time evolution of temperature (Eq. 1, term I) and an external heat source (Eq. 1, term V) for a well-mixed water column (see Caveats below). We assumed $\Delta \mathrm{H}$ is the primary oscillating component of $\Delta \mathrm{T}_{\text {heat }}$ and derived the scaling expression in Eq. D (Table 1) following the approach described above.

The scaling expression for $\Delta \mathrm{SC}_{\text {evap }}$ (Table $1, \mathrm{Eq}$. $\mathrm{E}$ ) is based on a simple mass balance that assumes that the integral of SC over the depth remains constant as water elevation changes due to evaporation. The evaporation rate, $\mathrm{E}_{\mathrm{v}}$, is assumed to be the primary oscillating component of $\Delta \mathrm{SC}_{\text {evap }}$.

Our scaling for $\Delta \mathrm{Chl}_{\text {growth }}$, the chl $a$ fluctuation caused by phytoplankton growth, is shown in Eq. F (Table 1) and derives from the assumption that the time evolution of phytoplankton biomass (Eq. 1, term I) is in balance with growth (Eq. 1, term IV). The phytoplankton specific net growth rate $(\mu)$ was assumed to be the primary oscillating component of $\Delta \mathrm{Chl}_{\text {growth }}$ and was calculated as a time-varying, depth-averaged function of tidal water column height, light-limited photosynthesis, and respiration loss. To be specific, intradaily variability in phytoplankton growth rate was calculated assuming phytoplankton cellular chlorophyll tracks carbon over the day. This assumption was based on discrete measurements of particulate organic carbon (POC) and chl $a$ (not shown) taken over a $30-\mathrm{h}$ period at three stations in the Mildred Island environment on September 5-6, 2001 (Doblin et al. unpublished data). The strong correlation of POC with chl $a\left(\mathrm{POC}=0.296+39.3 \times \operatorname{chl} a, \mathrm{r}^{2}=0.89\right)$ demonstrates that, across this environment and over a diurnal cycle, almost $90 \%$ of the variability in POC is explained by variability in chl $a$. The slope, which is close to published estimates of the phytoplankton cellular ratio of carbon to chl $a$ in the Delta (35, Sobczak et al. 2005; 32, Lopez et al. 2006) also suggests that variability in POC within this environment is associated with variability in phytoplankton.

In southern MI, zooplankton biomass and estimated grazing appeared to have a diurnal periodicity, while the periodicity in northern MI was unclear (Little personal communication). For this reason, $\Delta \mathrm{Chl}_{\mathrm{zp}}$ (the oscillation in chl $a$ attributable 
TABLE 2. Parameters used in scaling calculations. Dashes indicate the parameters that are assumed to be aperiodic. See Appendix for details on calculation of parameters and scales.

\begin{tabular}{|c|c|c|c|c|c|}
\hline Parameter & Units & Location & Period $(\mathrm{h})$ & Value & Description \\
\hline \multirow[t]{3}{*}{$\hat{\mathrm{u}}$} & $\mathrm{m} \mathrm{s}^{-1}$ & North & 12.4 & 0.11 & Oscillation amplitude for streamwise current velocity \\
\hline & & South & 12.4 & 0.012 & \\
\hline & & & 24.0 & $9.4 \times 10^{-3}$ & \\
\hline$\hat{\mathrm{v}}$ & $\mathrm{m} \mathrm{s}^{-1}$ & South & 24.0 & $8.0 \times 10^{-3}$ & Oscillation amplitude for transverse current velocity \\
\hline \multirow[t]{2}{*}{$\partial \mathrm{SC} / \partial \mathrm{x}$} & $\mathrm{mS} \mathrm{cm}{ }^{-1} \mathrm{~m}^{-1}$ & North & - & $1.3 \times 10^{-5}$ & Streamwise SC gradient \\
\hline & & South & - & $1.2 \times 10^{-5}$ & \\
\hline$\partial \mathrm{SC} / \partial \mathrm{y}$ & $\mathrm{mS} \mathrm{cm}{ }^{-1} \mathrm{~m}^{-1}$ & South & - & $8.3 \times 10^{-6}$ & Transverse SC gradient \\
\hline \multirow{2}{*}{$\partial \mathrm{T} / \partial \mathrm{x}$} & ${ }^{\circ} \mathrm{C} \mathrm{m}^{-1}$ & North & - & $1.6 \times 10^{-4}$ & Streamwise $\mathrm{T}$ gradient \\
\hline & & South & - & $3.9 \times 10^{-4}$ & \\
\hline$\partial \mathrm{T} / \partial \mathrm{y}$ & ${ }^{\circ} \mathrm{C} \mathrm{m}^{-1}$ & South & - & $4.7 \times 10^{-4}$ & Transverse $\mathrm{T}$ gradient \\
\hline \multirow[t]{2}{*}{$\partial \mathrm{Chl} / \partial \mathrm{x}$} & $\mu \mathrm{g} \mathrm{l}^{-1} \mathrm{~m}^{-1}$ & North & - & $9.0 \times 10^{-4}$ & Streamwise chl $a$ gradient \\
\hline & & South & - & $2.3 \times 10^{-3}$ & \\
\hline$\partial \mathrm{Chl} / \partial \mathrm{y}$ & $\mu \mathrm{g} \mathrm{l}^{-1} \mathrm{~m}^{-1}$ & South & - & $5.7 \times 10^{-3}$ & Transverse chl $a$ gradient \\
\hline \multirow[t]{3}{*}{$\hat{\mathrm{u}}_{* \mathrm{cs}}$} & $\mathrm{m} \mathrm{s}^{-1}$ & North & 6.2 & $1.5 \times 10^{-3}$ & $\begin{array}{l}\text { Oscillation amplitude for shear velocity associated with } \\
\text { current shear }\end{array}$ \\
\hline & & South & 24.0 & $9.0 \times 10^{-4}$ & \\
\hline & & & 12.4 & $6.0 \times 10^{-4}$ & \\
\hline$\hat{\mathrm{u}}_{* \text { wind }}$ & $\mathrm{m} \mathrm{s}^{-1}$ & Both & 24.0 & $3.0 \times 10^{-3}$ & $\begin{array}{l}\text { Oscillation amplitude for shear velocity associated with } \\
\text { wind stress }\end{array}$ \\
\hline \multirow[t]{2}{*}{$\partial \mathrm{SC} / \partial \mathrm{z}$} & $\mathrm{mS} \mathrm{cm}{ }^{-1} \mathrm{~m}^{-1}$ & North & - & $1.3 \times 10^{-4}$ & Vertical SC gradient \\
\hline & & South & - & $1.9 \times 10^{-3}$ & \\
\hline \multirow[t]{2}{*}{$\partial \mathrm{T} / \partial \mathrm{z}$} & ${ }^{\circ} \mathrm{C} \mathrm{m}^{-1}$ & North & - & $1.9 \times 10^{-3}$ & Vertical $\mathrm{T}$ gradient \\
\hline & & South & - & $5.3 \times 10^{-2}$ & \\
\hline \multirow[t]{2}{*}{$\partial \mathrm{Chl} / \partial \mathrm{z}$} & $\mu \mathrm{g} \mathrm{l}^{-1} \mathrm{~m}^{-1}$ & North & - & $7.8 \times 10^{-2}$ & Vertical chl $a$ gradient \\
\hline & & South & - & 1.3 & \\
\hline \multirow{2}{*}{$\mathrm{Ri}_{\mathrm{g}}$} & - & North & - & 0.16 & Gradient Richardson Number \\
\hline & & South & - & 0.46 & \\
\hline$\rho_{\mathrm{a}}$ & $\mathrm{kg} \mathrm{m}^{-3}$ & Both & - & 1.225 & Density of air \\
\hline$\rho_{\mathrm{o}}$ & $\mathrm{kg} \mathrm{m}^{-3}$ & Both & - & 1,000 & Reference density for water \\
\hline$C_{D}$ & - & Both & - & $1.0 \times 10^{-3}$ & Drag coefficient at water surface \\
\hline \multirow[t]{3}{*}{$\overline{\mathrm{h}}$} & $\mathrm{m}$ & $\begin{array}{l}\text { North } \\
\quad \text { (local) }\end{array}$ & - & 14.4 & Temporally averaged water column height \\
\hline & & $\begin{array}{l}\text { North } \\
\text { (Lagrangian) }\end{array}$ & - & 7.0 & \\
\hline & & South & - & 5.2 & \\
\hline \multirow[t]{2}{*}{$\Delta \mathrm{z}$} & $\mathrm{m}$ & North & - & 9.3 & $\begin{array}{l}\text { Vertical distance from water surface to mid point } \\
\text { between sensors }\end{array}$ \\
\hline & & South & - & 3.5 & \\
\hline \multirow[t]{2}{*}{$\Delta \hat{\mathrm{H}}$} & cal $\mathrm{cm}^{-2} \mathrm{~d}^{-1}$ & North & 24.0 & 1,029 & Oscillation amplitude for atmospheric heat flux \\
\hline & & South & 24.0 & 1,018 & \\
\hline$c_{\mathrm{p}}$ & cal g ${ }^{-1}{ }^{\circ} \mathrm{C}^{-1}$ & Both & - & 1 & Specific heat of water \\
\hline \multirow[t]{2}{*}{$\hat{\mathrm{E}}_{\mathrm{v}}$} & $\mathrm{cm} \mathrm{d}^{-1}$ & North & 24.0 & 0.24 & Oscillation amplitude for evaporation rate \\
\hline & & South & 24.0 & 0.25 & \\
\hline $\mathrm{SC}_{\mathrm{o}}$ & $\mathrm{mS} \mathrm{cm} \mathrm{cm}^{-1}$ & Both & - & 0.4 & Initial SC for scaling calculation (taken as mean) \\
\hline$\hat{\mu}$ & $\mathrm{d}^{-1}$ & Both & 24.0 & 0.4 & Oscillation amplitude for phytoplankton growth rate \\
\hline \multirow[t]{2}{*}{$\mathrm{Chl}_{\mathrm{o}}$} & $\mu \mathrm{g} 1^{-1}$ & North & - & 3.0 & Initial chl $a$ for scaling calculation (taken as mean) \\
\hline & & South & - & 12.0 & \\
\hline \multirow[t]{2}{*}{$\hat{\mu}_{\mathrm{zp}}$} & $d^{-1}$ & North & - & - & $\begin{array}{l}\text { Oscillation amplitude for zooplankton specific grazing } \\
\text { rate }\end{array}$ \\
\hline & & South & 24.0 & 0.07 & \\
\hline
\end{tabular}

to zooplankton grazing, Table 1, Eq. G) was estimated only for the south. The expression for $\Delta \mathrm{Chl}_{\mathrm{zp}}$ takes the same form as for growth. Benthic grazing by bivalve clams can be a significant sink for phytoplankton biomass in parts of the MI region (Lucas et al. 2002), but because clam biomass within MI was generally low (Thompson unpublished data) and the hourly-scale periodicity in clam feeding is not well understood for this environment, we did not consider its effects on short-term chl $a$ variability.
Parameters for the scaling calculations are summarized in Table 2. Details of the scaling derivations are in the Appendix.

\section{Observed Variability}

\section{DOMINANT PERIODS OF INTRADAILY VARIABILITY}

$\mathrm{SC}, \mathrm{T}$, and chl $a$ varied over time scales ranging from hours to weeks; since the focus here is on hourly scale variability, we show only excerpts of the longer time series obtained (Figs. 4 and 5). Power 

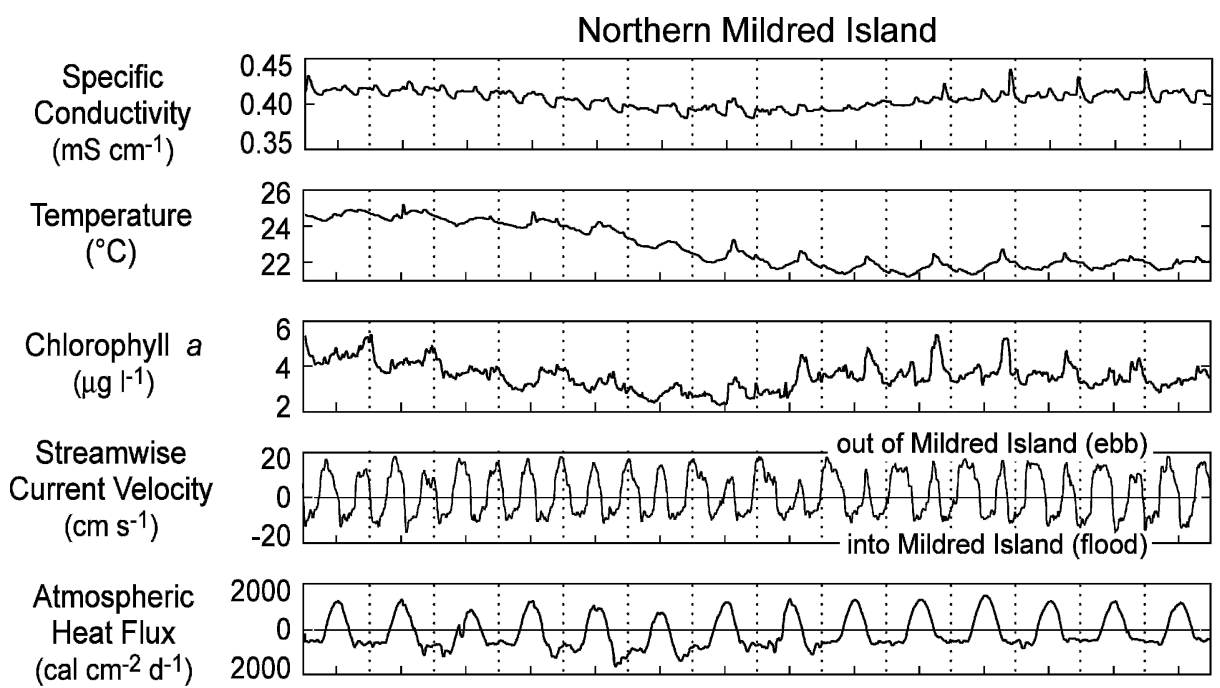
Wind Speed $\left(\mathrm{m} \mathrm{s}^{-1}\right)$

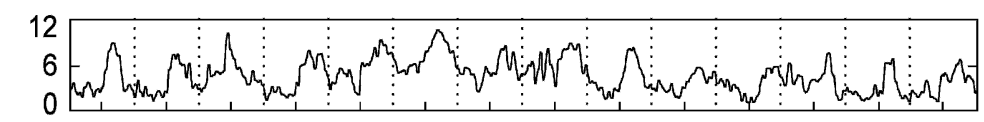

Stage
$(\mathrm{m})$

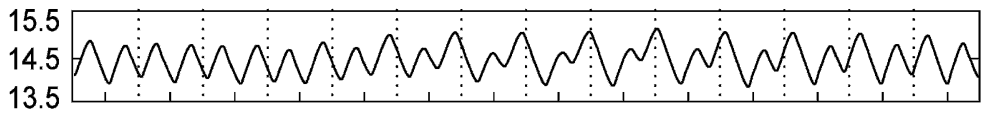

$\partial \mathrm{SC} / \partial \mathrm{t}$
$\left(\mathrm{mS} \mathrm{cm} \mathrm{cm}^{-1} \mathrm{~d}^{-1}\right)$

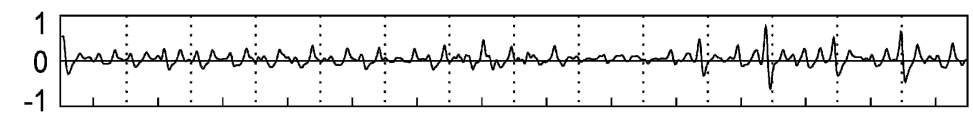

$\partial \mathrm{T} / \partial \mathrm{t}$
$\left({ }^{\circ} \mathrm{C} \mathrm{d} \mathrm{d}^{-1}\right)$
$\partial \mathrm{Chl} / \partial \mathrm{t}$
$\left(\mu \mathrm{g} \mathrm{l}^{-1} \mathrm{~d}^{-1}\right)$

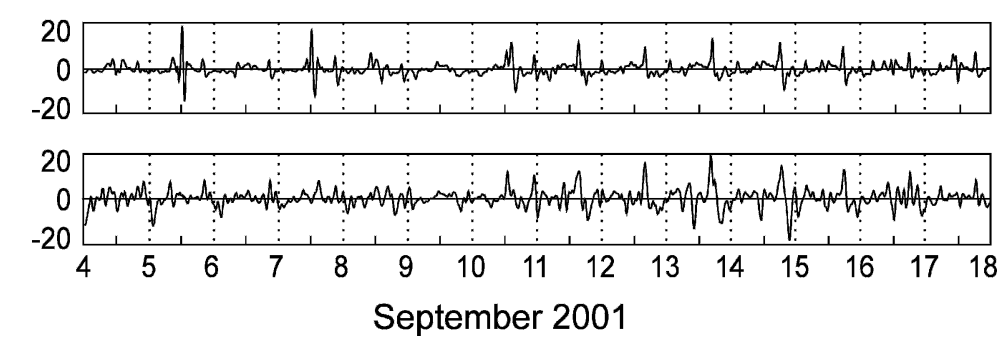

Fig. 4. Time series data collected or calculated for northern Mildred Island: specific conductivity ${ }^{*}$, water temperature ${ }^{*}$, chlorophyll $a^{*}$, streamwise current velocity ${ }^{*}$, calculated atmospheric heat flux, wind speed ${ }^{*}$, stage ${ }^{*}$, and first time derivatives of specific conductivity, water temperature, and chlorophyll $a .{ }^{*}$ indicates data shown were 1-h median filtered for easier visual identification of dominant frequencies. Data shown are excerpts of longer time series.

spectra quantitatively identified the dominant periods of intradaily variability (Fig. 6). For simplicity, we display measurements and power spectra for the upper water column; temporal variations in SC, T, and chl $a$ in the lower water column were generally similar.

At the northern site, the dominant period was $12.4 \mathrm{~h}$ for $\mathrm{SC}$ (the semidiurnal $\mathrm{M}_{2}$ tidal period); the next most dominant period was $6.2 \mathrm{~h}$, corresponding to the $\mathrm{M}_{4}$ partial tide, generally the largest nonlinear tidal constituent in the Delta (Figs. 4 and $6)$. At the southern site, SC variability was characterized by the $24.0 \mathrm{~h}$ period (Figs. 5 and 6). Intradaily variability in $\mathrm{T}$ was dominated by the $24.0 \mathrm{~h}$ period in both the north and south. Chl $a$ was characterized by a $24.0 \mathrm{~h}$ period in the south; in the north, the $12.4 \mathrm{~h}$ and $24.0 \mathrm{~h}$ periods posed comparable contributions to the signal, indicating a mixed diurnal-semidiurnal periodicity (Fig. 6). Figure 4 shows that the periodicity of northern chl $a$ appeared to oscillate between diurnal (e.g., September 4-10) and semidiurnal (e.g., September 12-16).

The amplitude of hourly scale variability in chl $a$ was comparable to the amplitude of the dailyweekly scale variability, with largest fluctuations evident in the south (Order of magnitude[1-10] $\mu \mathrm{g} \mathrm{l}^{-1}$ in the south, Order[1] $\mu \mathrm{g} \mathrm{l}^{-1}$ in the north, Figs. 4 and 5). The diurnal $\mathrm{T}$ oscillation was also substantial (Order[1] ${ }^{\circ} \mathrm{C}$ ) and comparable to daily to weekly scale variability; largest amplitudes gener- 

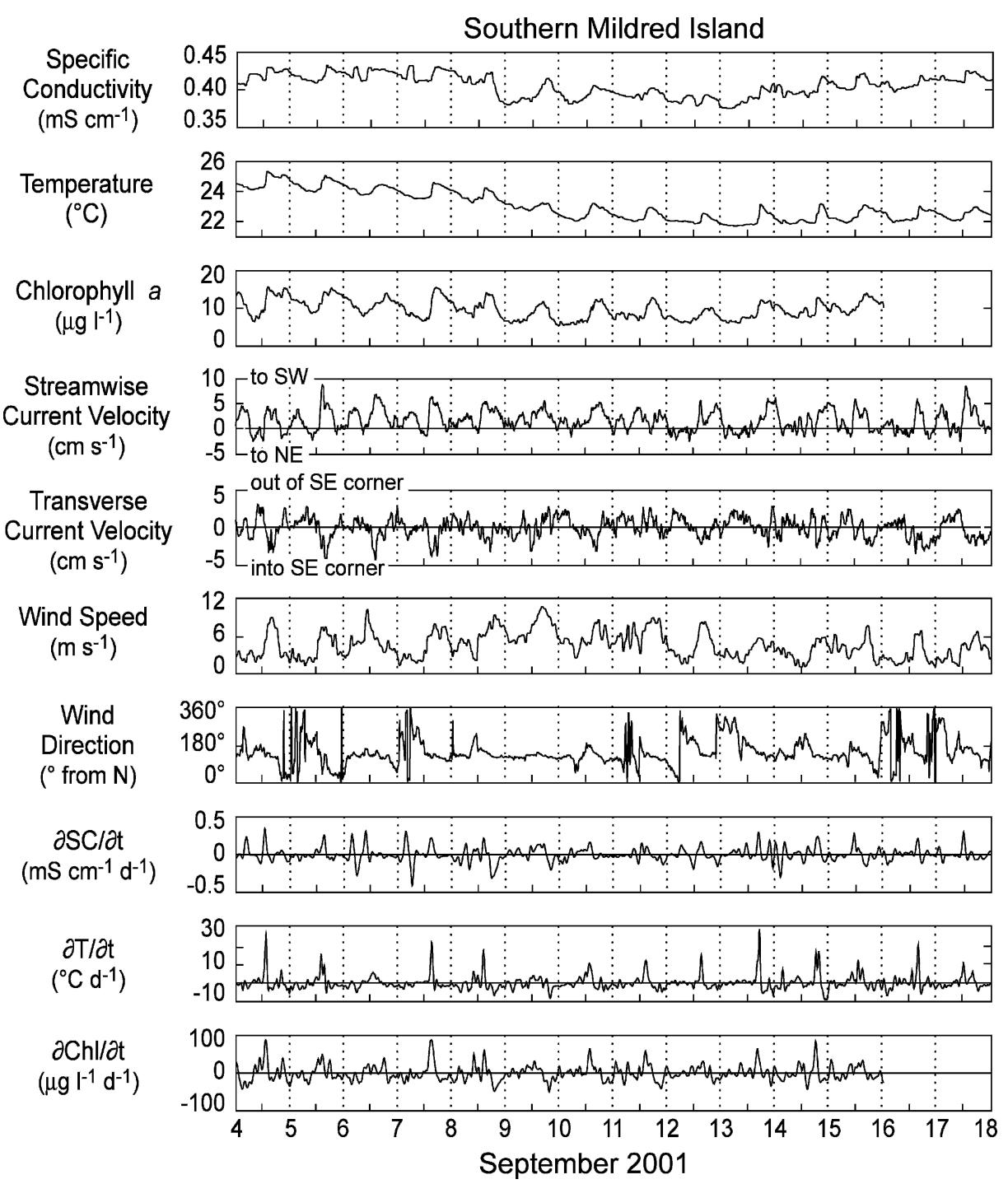

Fig. 5. Time series data collected or calculated for southern Mildred Island: specific conductivity ${ }^{*}$, water temperature*, chlorophyll $a^{*}$, streamwise current velocity ${ }^{*}$, transverse current velocity ${ }^{*}$, wind speed ${ }^{*}$, wind direction, and first time derivatives of specific conductivity, water temperature, and chlorophyll $a{ }^{*}$ indicates data shown were 1-h median filtered for easier visual identification of dominant frequencies. Data shown are excerpts of longer time series.

ally occurred in the south. SC displayed the smallest amplitude of hourly scale relative to daily or weekly scale variability, with comparably sized fluctuations in the north and south (Order[0.01] $\mathrm{mS} \mathrm{cm}^{-1}$ ).

The dominant periods for $\mathrm{u}$ and $\mathrm{v}$ in the north were $12.4 \mathrm{~h}$ (Fig. 6). In the south, u contained a primary semidiurnal component and a secondary diurnal component (Fig. 6) and was almost unidirectional (Fig. 5), suggesting that the southern site was located within a gyre. A diurnal bidirectional transverse current was superimposed on the gyre. Large pulses in $\mathrm{v}$ toward the southeast corner generally occurred in the afternoon and corresponded to strong winds blowing toward the southeast (e.g., September 4). $\Delta \mathrm{H}$ (calculated for the north) and $U_{\text {wind }}$ were both characterized by the $24.0 \mathrm{~h}$ period. Air temperature (not shown) and PAR (not shown) were diurnal, as expected. Table 3 summarizes the dominant periods of intradaily variability.

\section{Time Variability of Characteristic Periods}

To explore the evolving periodicity of chl $a$ in the north at intermediate time scales, we used sliding 3-d autocorrelations (Fig. 7). An example of clear diurnal periodicity is shown in the autocorrelation for September 17-19, where positive correlation is clearly evident at multiples of $24 \mathrm{~h}$. Earlier in the 

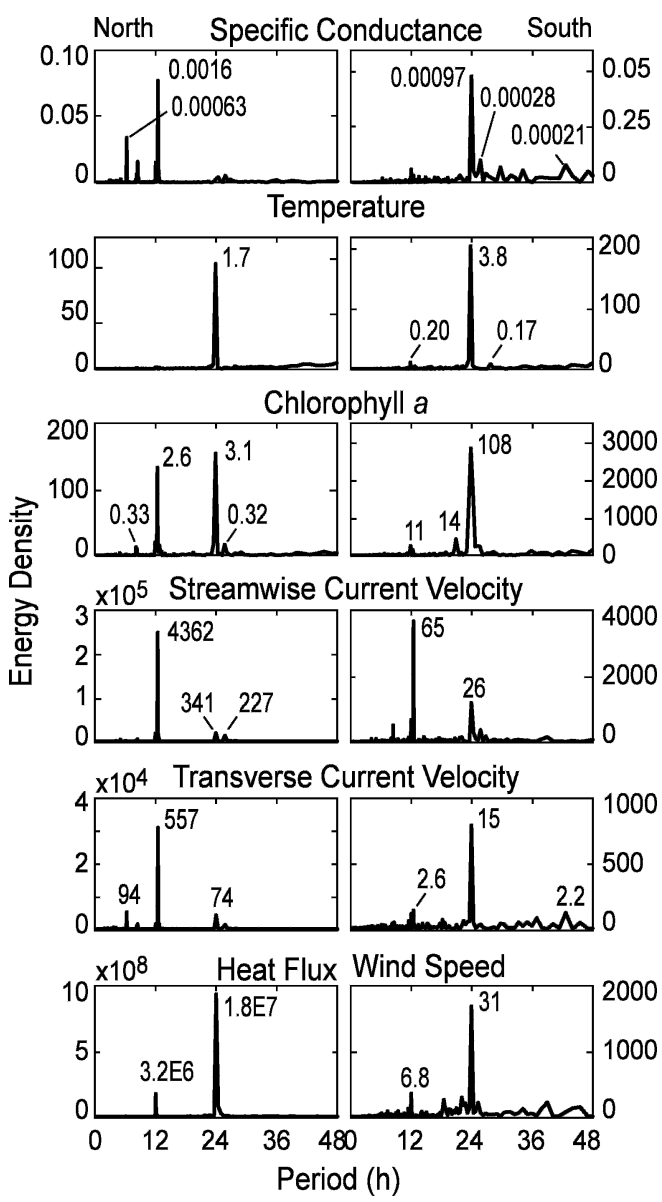

Fig. 6. Power spectra at north and south stations for specific conductance, water temperature, chlorophyll $a$, streamwise current velocity, and transverse current velocity. Heat flux was calculated for the northern site. Wind speed was measured in southern Mildred Island. Each numerical value next to a peak represents the variance associated with that peak.

TABLE 3. Summary of intradaily periods of variability for three water quality constituents and environmental forcings at Mildred Island, summer-fall 2001. Periods were identified using power spectra calculated for upper water column measurements of each quantity (see Fig. 6). Where two values are listed, two periods appeared significant, and the order of periodicities reflects relative variance.

\begin{tabular}{llll}
\hline & \multicolumn{3}{c}{ Dominant Intradaily Period (h) } \\
\cline { 2 - 4 } \multicolumn{1}{c}{ Quantity } & \multicolumn{1}{c}{ North } & \multicolumn{1}{c}{ South } & $\begin{array}{c}\text { Mildred } \\
\text { Island }\end{array}$ \\
\hline $\begin{array}{l}\text { Specific conductance } \\
\quad \text { SC) }\end{array}$ & $12.4 / 6.2$ & 24.0 & - \\
Water temperature $(\mathrm{T})$ & 24.0 & 24.0 & - \\
Chlorophyll $a(\mathrm{chl} a)$ & $24.0 / 12.4$ & 24.0 & - \\
Streamwise velocity $(\mathrm{u})$ & 12.4 & $12.4 / 24.0$ & - \\
Transverse velocity $(\mathrm{v})$ & 12.4 & 24.0 & - \\
Wind speed $\left(\mathrm{U}_{\text {wind }}\right)$ & - & - & 24.0 \\
Heat flux $(\Delta \mathrm{H})$ & - & - & 24.0 \\
\hline
\end{tabular}

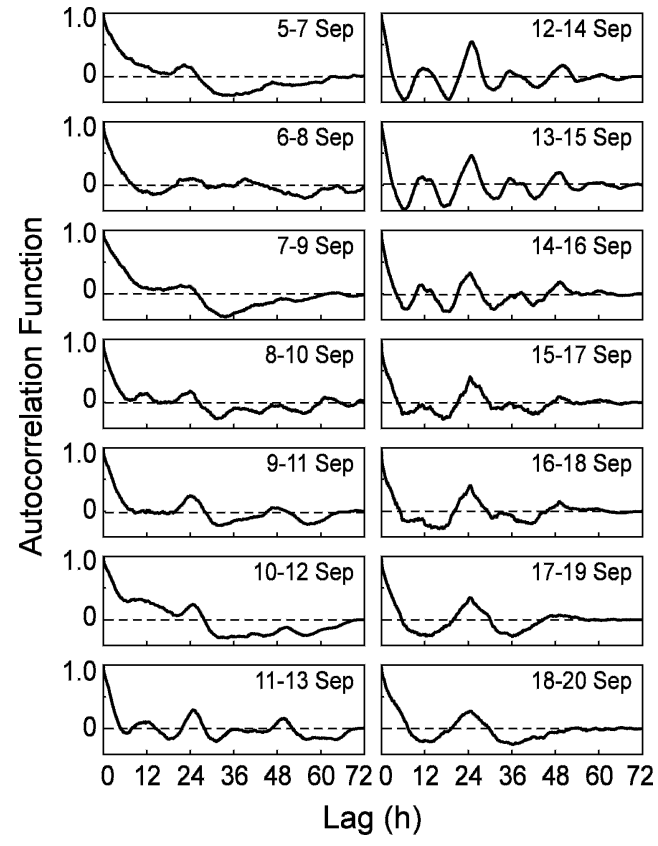

Fig. 7. Sliding 3-day autocorrelations calculated for chlorophyll $a$ in the upper water column at the north station. Successive panels demonstrate the evolution in periodicity for this quantity at this location.

data set, on September 12-14, a semidiurnal periodicity is evident due to positive correlations at multiples of approximately $12 \mathrm{~h}$, but with a diurnal periodicity superimposed (the correlations for lags of multiples of $24 \mathrm{~h}$ were larger than for odd multiples of $12 \mathrm{~h}$ ). Collectively, the autocorrelations show the periodicity of northern chl $a$ transitioning between semidiurnal and diurnal.

\section{WATER QUALITY MAPS}

Sample water quality maps are shown in Fig. 8. Derived from circuit measurements centered temporally around slack after flood, these sample maps demonstrate spatial characteristics of SC, T, and chl $a$ generally visible on other maps. All three constituents generally increased in magnitude toward the south. Spatial gradients of $\mathrm{T}$ and chl $a$ appeared sharper and more complex in the south than in the north. A plume appeared near the southern opening containing higher SC and lower chl $a$ than the surrounding environment. Overall, SC was slightly higher in the west; T and chl $a$ were generally higher in the east.

\section{MECHANISMS OF VARIABILITY}

The results above demonstrated the existence of large amplitude intradaily variability in three transported scalars and that the periods of variability differed between scalars, spatial locations, and time 

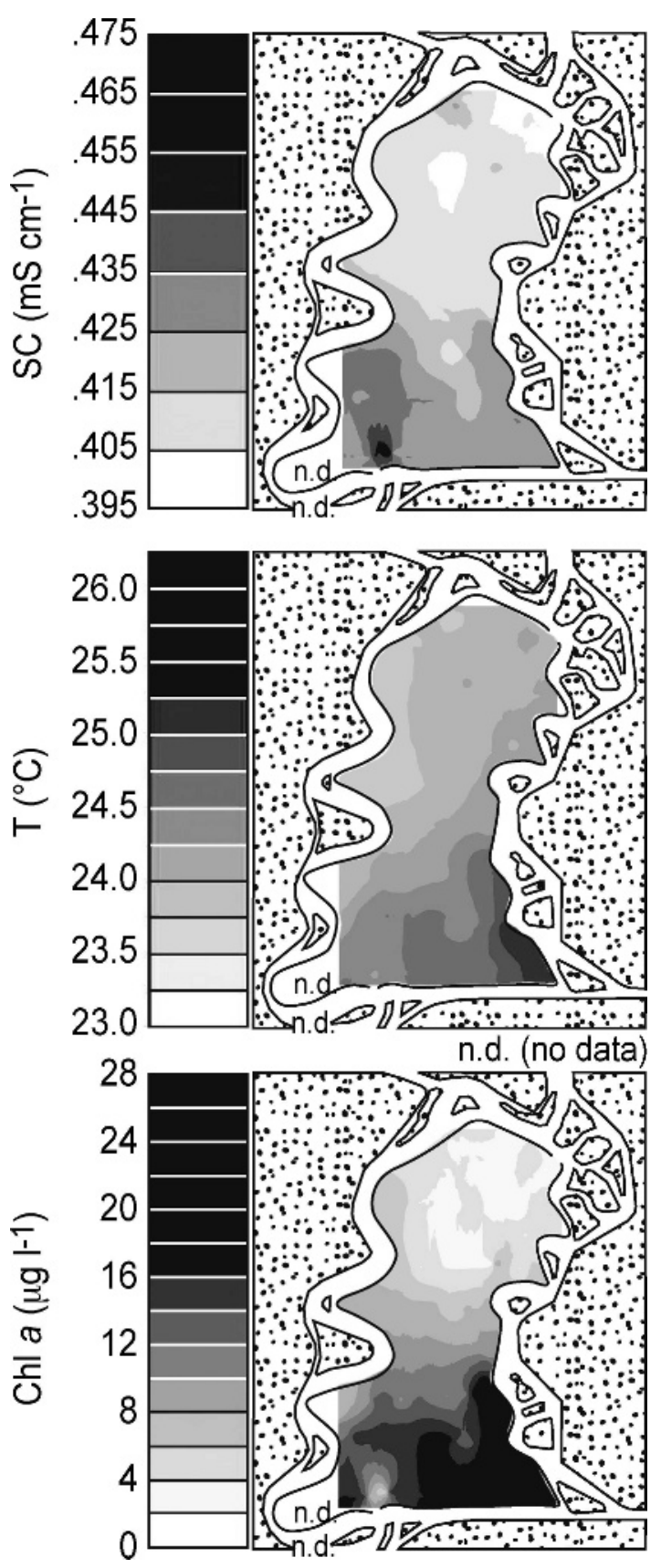

Fig. 8. Sample water quality maps interpolated from mapping circuits in Mildred Island during September 2001. The maps shown represent the third of five circuits performed during consecutive slack tides, occurred between 8:45 pm and 10:00 pm PDT on September 5 and were centered temporally on a slack tide after flood. Stippled areas represent land.

periods. In this section we apply a scaling approach to evaluate the mechanisms responsible for that variability. $\Delta \mathrm{C}$ estimates (where $\mathrm{C}$ is $\mathrm{SC}, \mathrm{T}$, or chl $a$ ) are summarized in Table 4 and Fig. 9 for horizontal advection, vertical mixing, evaporation, atmospheric heat flux, and phytoplankton growth and pelagic
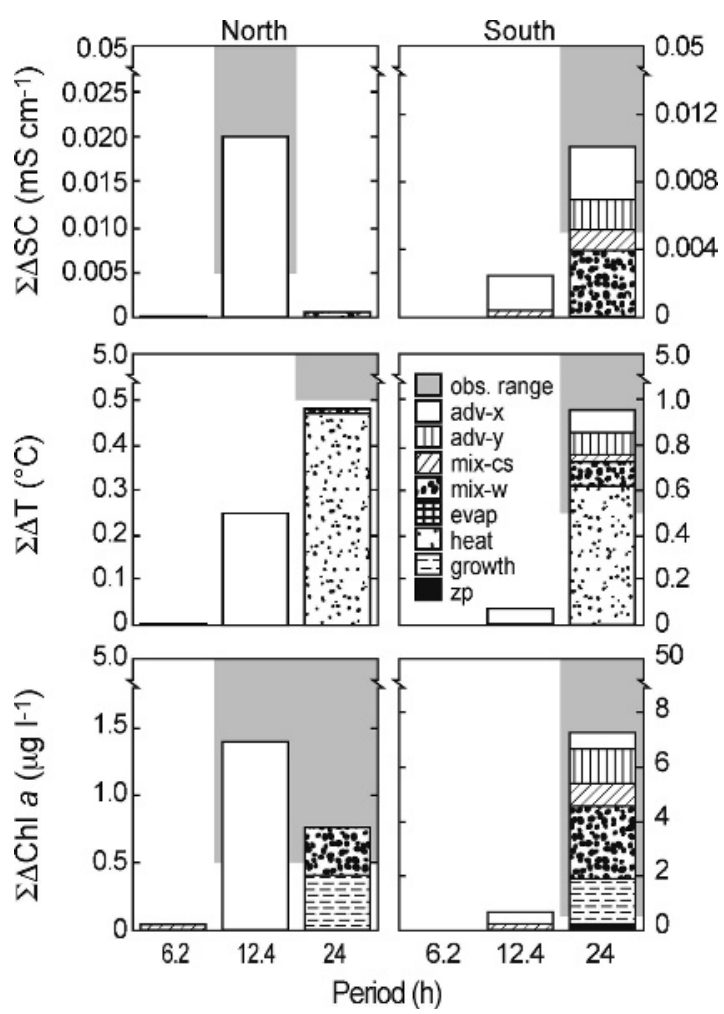

Fig. 9. Stacked bar graphs representing the individual and collective oscillation magnitudes for specific conductivity, water temperature, and chlorophyll $a$ caused by various processes in northern and southern Mildred Island, 2001. Processes represented are streamwise advection (adv-x), transverse advection (adv-y), vertical mixing caused by current shear (mix-cs), vertical mixing caused by wind (mix-w), evaporation (evap, for specific conductivity only), atmospheric heating (heat, for temperature only), phytoplankton growth (growth, for chlorophyll $a$ only), and zooplankton grazing (zp, for chlorophyll $a$ only). Gray shaded regions represent the observed order-of-magnitude range and period of scalar oscillations. These results are shown quantitatively in Table 4.

consumption. To provide a sense of the total amount of variability driven by processes sharing a given period, we calculate $\Sigma \Delta \mathrm{C}$, the sum of $\Delta \mathrm{Cs}$ caused by all processes with that period. In the following sections, we discuss $\Delta \mathrm{Cs}$ associated with individual processes, compare the size and periodicity of the dominant $\Sigma \Delta \mathrm{C}$ to the observed magnitude and period of variability identified with spectral analysis, evaluate whether the scaling is consistent with the observed variability, and return to the original time series and time derivatives to explore specific mechanisms underlying the observed variability.

\section{Specific Conductivity, North}

In the north, $\Delta \mathrm{SC}_{\mathrm{adv}-\mathrm{x}}$ was $0.02 \mathrm{mS} \mathrm{cm} \mathrm{cm}^{-1}$, which is on the order of the observed oscillations in SC and 100-1,000 times larger than fluctuations potentially caused by vertical mixing or evaporation (Fig. 9 and 
TABLE 4. Scaling based estimates of scalar oscillation amplitude $(\Delta \mathrm{C})$ caused by individual processes and at individual periods. $\mathrm{C}$ is either specific conductance, temperature, or chlorophyll $a$, as indicated. $\Delta \mathrm{C}_{\text {adv-x }}, \Delta \mathrm{C}_{\text {adv-y }}, \Delta \mathrm{C}_{\text {mix-cs }}, \Delta \mathrm{C}_{\text {mix-wind }}, \Delta \mathrm{C}_{\text {evap }}, \Delta \mathrm{C}_{\text {heat }}, \Delta \mathrm{C}_{\text {growth }}$, and $\Delta \mathrm{C}_{\mathrm{zp}}$, respectively, are the oscillation amplitudes associated with streamwise advection, transverse advection, vertical mixing caused by current shear, vertical mixing caused by wind, evaporation (for specific conductance only), atmospheric heating (for temperature only), growth (for chl $a$ only), and zooplankton grazing (for chl $a$ only). $\Sigma \Delta \mathrm{C}$ is the sum of all $\Delta \mathrm{Cs}$ for a particular constituent and period. Obs. $\Delta \mathrm{C}$ is the order of magnitude $\Delta \mathrm{C}$ for the observations. - indicates that process and period were either irrelevant or insignificant.

\begin{tabular}{|c|c|c|c|c|c|c|c|c|c|c|c|}
\hline Scalar, C & Period (h) & $\Delta \mathrm{C}_{\mathrm{adv}-\mathrm{x}}$ & $\Delta \mathrm{C}_{\text {adv-y }}$ & $\Delta \mathrm{C}_{\text {mix-cs }}$ & $\Delta \mathrm{C}_{\text {mix-wind }}$ & $\Delta \mathrm{C}_{\text {evap }}$ & $\Delta \mathrm{C}_{\text {heat }}$ & $\Delta \mathrm{C}_{\text {growth }}$ & $\Delta \mathrm{C}_{\mathrm{zp}}$ & $\Sigma \Delta \mathrm{C}$ & $\begin{array}{c}\text { Obs. } \Delta \mathrm{C} \\
\text { Order }\end{array}$ \\
\hline \multicolumn{12}{|c|}{$\mathrm{SC}\left(\mathrm{mS} \mathrm{cm} \mathrm{cm}^{-1}\right)$} \\
\hline \multirow[t]{3}{*}{ North } & 6.2 & - & - & $7.6 \times 10^{-5}$ & - & - & - & - & - & $7.6 \times 10^{-5}$ & - \\
\hline & 12.4 & 0.02 & - & - & - & - & - & - & - & 0.02 & {$[0.01]$} \\
\hline & 24.0 & - & - & - & $5.9 \times 10^{-4}$ & $4.4 \times 10^{-5}$ & - & - & - & $6.3 \times 10^{-4}$ & - \\
\hline \multirow[t]{3}{*}{ South } & 6.2 & - & - & - & - & - & - & - & - & - & - \\
\hline & 12.4 & 0.0021 & - & $4.0 \times 10^{-4}$ & - & - & - & - & - & 0.0025 & - \\
\hline & 24.0 & 0.0031 & 0.0018 & 0.0012 & 0.0039 & $6.1 \times 10^{-5}$ & - & - & - & 0.01 & {$[0.01]$} \\
\hline \multicolumn{12}{|l|}{$\mathrm{T}\left({ }^{\circ} \mathrm{C}\right)$} \\
\hline \multirow[t]{3}{*}{ North } & 6.2 & - & - & 0.0011 & - & - & - & - & - & 0.0011 & - \\
\hline & 12.4 & 0.25 & - & - & - & - & - & - & - & 0.25 & - \\
\hline & 24.0 & - & - & - & 0.0086 & - & 0.47 & - & - & 0.48 & [1] \\
\hline \multirow[t]{3}{*}{ South } & 6.2 & - & - & - & - & - & - & - & - & - & - \\
\hline & 12.4 & 0.066 & - & 0.011 & - & - & - & - & - & 0.077 & - \\
\hline \multirow{2}{*}{\multicolumn{12}{|c|}{$\operatorname{chl} a\left(\mu \mathrm{g} \mathrm{l}^{-1}\right)$}} \\
\hline & & & & & & & & & & & \\
\hline \multirow[t]{3}{*}{ North } & 6.2 & - & - & 0.045 & - & - & - & - & - & 0.045 & - \\
\hline & 12.4 & 1.4 & - & - & - & - & - & - & - & 1.4 & [1] \\
\hline & 24.0 & - & - & - & 0.35 & - & - & 0.41 & - & 0.76 & - \\
\hline \multirow[t]{3}{*}{ South } & 6.2 & - & - & - & - & - & - & - & - & - & - \\
\hline & 12.4 & 0.39 & - & 0.27 & - & - & - & - & - & 0.66 & - \\
\hline & 24.0 & 0.59 & 1.3 & 0.8 & 2.7 & - & - & 1.6 & 0.27 & 7.3 & [1-10] \\
\hline
\end{tabular}

Table 4). Streamwise advection was the only semidiurnal process at the northern site, matching the periodicity in SC identified with spectral analysis (Fig. 6 and Table 3). Scaling suggests streamwise advection is the single most important process causing observed oscillations in SC at this location. The original time series and time derivatives help explain the specific mechanism behind this variability. Negative $\partial \mathrm{SC} / \partial \mathrm{t}$ in the north generally occurred during mid to late flood, whereas positive or zero $\partial \mathrm{SC} / \partial \mathrm{t}$ typically occurred between early ebb and early flood (e.g., September 6, Fig. 4). Ancillary SC measurements in northern Middle River and Connection Slough, two water sources for MI during a flood tide, indicate that SC in Connection Slough was significantly higher than in Middle River (see Fig. 2 for station locations, data not shown). During some flood tides, high SC Connection Slough water appeared to initially enter MI (causing positive $\partial \mathrm{SC} / \partial \mathrm{t}$ during early flood), followed by much fresher Middle River water (causing a period of negative $\partial \mathrm{SC} / \partial \mathrm{t}$ during the remainder of the flood). During ebb, $\partial \mathrm{SC} / \partial \mathrm{t}$ in the north was typically either positive or about zero, due to northward advection of interior gradients past the sensor (Fig. 8).

\section{TEMPERATURe, NORTH}

The largest estimated $\Delta \mathrm{T}$ in the north was associated with atmospheric heating. $\Delta \mathrm{T}_{\text {heat }}$ was approximately twice $\Delta \mathrm{T}_{\mathrm{adv}-\mathrm{x}}$ and about 50 times greater than $\Delta \mathrm{T}_{\text {mix-wind }}$, making $\Sigma \Delta \mathrm{T}$ for $\tau=24.0 \mathrm{~h}$ about twice $\Sigma \Delta \mathrm{T}$ for $\tau=12.4 \mathrm{~h}$ (Fig. 9 and Table 4). The order-of-magnitude similarity between $\Sigma \Delta$ Ts for the two periods might lead us to expect a primary diurnal periodicity with a secondary though significant semidiurnal component, but spectral analysis showed only a diurnal component (Fig. 6 and Table 3). Another discrepancy between scaling and observation exists in the magnitude of $\Sigma \Delta \mathrm{T}$ for $\tau=24.0 \mathrm{~h}\left(0.48^{\circ} \mathrm{C}\right)$, which was slightly smaller than the observed $\Delta \mathrm{T}\left(\operatorname{Order}[1]^{\circ} \mathrm{C}\right)$.

This discrepancy is likely due to an underestimation of $\Delta T_{\text {heat }}$ that is linked to the definition of the vertical length scale $\bar{h}$. The scaling expression for $\Delta \mathrm{T}_{\text {heat }}$ is based on the assumption that the water column of height $\bar{h}$ is vertically well mixed, but multiple processes may combine to stratify the water column and reduce the effective $\overline{\mathrm{h}}$, increasing $\Delta \mathrm{T}_{\text {heat }}$ for the surface layer. In general, and as would be expected, positive $\partial \mathrm{T} / \partial \mathrm{t}$ occurred for several hours during the middle of every day (i.e., during the period of positive heat flux, Fig. 4). On particular days (e.g., September 5 and 7 ) $\partial \mathrm{T} / \partial \mathrm{t}$ became temporarily quite large. These large $\partial \mathrm{T} / \partial \mathrm{t}$ spikes coincided with a mid day or afternoon ebb tide, were enhanced when wind speed was small, and reversed when wind speed increased or the current direction reversed. Ebb tides, especially those occurring during or at the end of the daily heating period, transported the warm southern 
water northward past the northern instruments, causing an increase in northern T. Ancillary measurements showed that selective withdrawal of extra-warm surface water from near the eastern shore often occurred during ebb, causing warmer water to overlie cooler water from central MI (see Fig. 8 for west-east $\mathrm{T}$ gradient). This semidiurnal, advectively induced stratification would have effectively shortened the vertical length scale, especially if wind mixing was weak, and enhanced the ability of atmospheric heating to raise $\mathrm{T}$ in the upper water column. In this way, nonlinear reinforcement of heating by tidal currents and wind, which depends on the phasing between those processes, is not necessarily captured in the scaling analysis (because it treats processes separately) and may cause a larger diurnal fluctuation than predicted by $\Delta \mathrm{T}_{\text {heat }}$.

\section{Chlorophyll $a$, NORTH}

At the northern site, $\Sigma \Delta \mathrm{Chl}$ for $\tau=12.4 \mathrm{~h}$, which was driven entirely by streamwise advection, was approximately double $\Sigma \Delta \mathrm{Chl}$ for $\tau=24.0 \mathrm{~h}$, which was jointly driven by growth and wind-driven mixing (Fig. 9 and Table 4 ). The similarity between $\Sigma \Delta$ Chls for these two periods is consistent with the mixed diurnal-semidiurnal character of chl $a$ in the north identified with spectral analysis (Fig. 6 and Table 3). The magnitudes of both $\Sigma \Delta$ Chls were on the order of observed $\Delta \mathrm{Chl}$. The structured transition between diurnal and semi-diurnal periodicity demonstrated in Fig. 7 suggests a possible mechanistic explanation that involves the phasing of tides relative to daylight and phytoplankton growth. This phasing shifts over the same period as the spring-neap cycle, with the tides shifting by about $0.8 \mathrm{~h}$ each day relative to sunlight. On September 13-16, flood was centered roughly on the photoperiod and there were correspondingly two major negative $\partial \mathrm{Chl} / \partial \mathrm{t}$ periods per day (one due to the mid day flood tide and one at night; Fig. 4); on September 5-9, ebb or low slack was roughly centered on the photoperiod and there was only one major period of chl $a$ decrease per day (i.e., at night). This transition in the phasing of daylight with flood tides is consistent with the transition from semidiurnal to diurnal variability in the chl $a$ signal at this station (Fig. 7).

\section{All Constituents, South}

For the south site, scaling suggested that combined diurnal processes $(\Sigma \Delta \mathrm{C}$ for $\tau=24.0 \mathrm{~h})$ were an order of magnitude more important than combined semidiurnal processes $(\Sigma \Delta \mathrm{C}$ for $\tau=$ $12.4 \mathrm{~h}$ ) for all three constituents (Fig. 9 and Table 4). This is consistent with the diurnal periodicities identified by spectral analysis for all constituents in the south (Figs. 6 and 9, Tables 3 and 4). The magnitudes of $\Sigma \Delta \mathrm{C}$ for $\tau=24.0 \mathrm{~h}$ agreed with observed oscillation amplitudes (Fig. 9 and Table 4). Streamwise and transverse advection and both sources of vertical mixing appear to have contributed significantly to the diurnal variability of all three constituents. For SC, these processes were 100 times more important than evaporation. For T, the combined effect of the diurnal hydrodynamic processes was enhanced greatly by atmospheric heating. For chl $a$, hydrodynamically driven diurnal variability was enhanced by growth and zooplankton grazing. Even if the assumptions underlying our estimate of $\Delta \mathrm{Chl}_{\text {growth }}$ are not valid, scaling suggests that physical processes alone could account for the order-of-magnitude variability observed in southern chl $a$.

Positive spikes in the time derivatives of southern $\mathrm{SC}, \mathrm{T}$, and chl $a$ often co-occurred in the afternoon and coincided with simultaneous increases in wind speed, southwest streamwise flow, and southeast transverse flow (e.g., September 4, Fig. 5). As wind forcing increases in the afternoon, the surface mixed layer deepens and the thermocline moves past the fixed, submerged sensors, creating a sharp, sudden transition in scalar concentrations (manifested as a spike in the time derivative).

We conclude that streamwise transport, transverse transport, and especially wind-driven vertical mixing were potentially comparably important and may have, in combination, driven significant diurnal oscillations of scalars in the southern region. For $\mathrm{T}$, diurnal transport was probably enhanced by atmospheric heating, depending on the phasing. For chl $a$, the diurnal physical processes may have been amplified by phytoplankton growth and pelagic consumption.

\section{Caveats}

The scaling expressions for atmospheric heat flux, phytoplankton growth, and zooplankton grazing were based on numerous assumptions, including that of a vertically well-mixed water column. From comparison of near-bottom time series (not shown) to upper time series, as well as a few vertical profiles of $\mathrm{T}$ and chl $a$, we know that the water column experienced ephemeral stratification, typically lasting less than half a day. Our estimates for $\Delta \mathrm{T}_{\text {heat }}$ and $\Delta \mathrm{Chl}_{\text {growth }}$ could be underestimates if the upper sensors were located above a pycnocline, since heating and growth over the whole water column would be slower than for a shallower surface layer.

Horizontal scalar gradients were estimated from a 30-h study, which was affected by specific tidal, daylight, and wind conditions, and only provide a snapshot of the scalar spatial distributions. 
Although they are the best estimates available, gradients based on these surveys are really only estimates of conditions during the greater study period. Some quantities treated as constants in the scaling calculations (e.g., temperature gradients) may actually be periodic and could induce periodicities in observed scalars not accounted for in the scaling calculations.

\section{Discussion \\ CREATION OF ForTNIGHTLY VARIABILITY IN CHLOROPHYLL EXPORT}

The nature of chl $a$ export from MI could be important to the phytoplankton-poor Delta ecosystem, which is characterized by low phytoplankton productivity and biomass compared to tidal systems worldwide (Jassby et al. 2002; Sobczak et al. 2002). Long-term declines in native fish, phytoplankton biomass (Jassby et al. 2002), and native zooplankton (Kimmerer and Orsi 1996), coupled with work showing that phytoplankton is the dominant food source for the Delta's pelagic food web (Sobczak et al. 2002; Muller-Solger et al. 2003), suggest food limitation at the food web base as one factor contributing to declines in native juvenile fish (Bennett and Moyle 1996). Lopez et al. (2006) showed that anomalous phytoplankton-rich habitats such as MI may support pelagic secondary producers in adjacent phytoplankton-poor regions through tidal transport.

Past work (Taylor and Stephens 1993; Lucas et al. 1999a,b; Vaulot and Marie 1999; Lucas and Cloern 2002) has shown how nonlinear interactions at fine temporal scales can govern long-term mean dynamics in transported quantities like phytoplankton. The dispersive export of phytoplankton biomass from MI is one example of such cross-scale linkages in this data set.

The net dispersive flux of chl $a$ at the northern station appears governed by the interaction between tides and the period of phytoplankton increase during the day. Ebb tides brought higher chl $a$ water from southern MI to northern MI, regulating the biomass available for export at the northern site (see Fig. 8 for gradient). Diurnally varying southern chl $a$ would generally reach maximal levels in the late afternoon or early evening (Fig. 5). Northern chl $a$, and the export of that biomass, depended to a large extent on the timing of ebb relative to maximum southern chl $a$. We use surface PAR as a surrogate for diurnal phytoplankton increase and calculate its correlation with discharge $Q$ (Fig. 10). The time series of $Q \times$ PAR (where positive $Q$ represents ebb) highlights the temporal relationship between tides and daylight; positive $\mathrm{Q} \times \mathrm{PAR}$ corresponds to ebbs occurring during daylight,
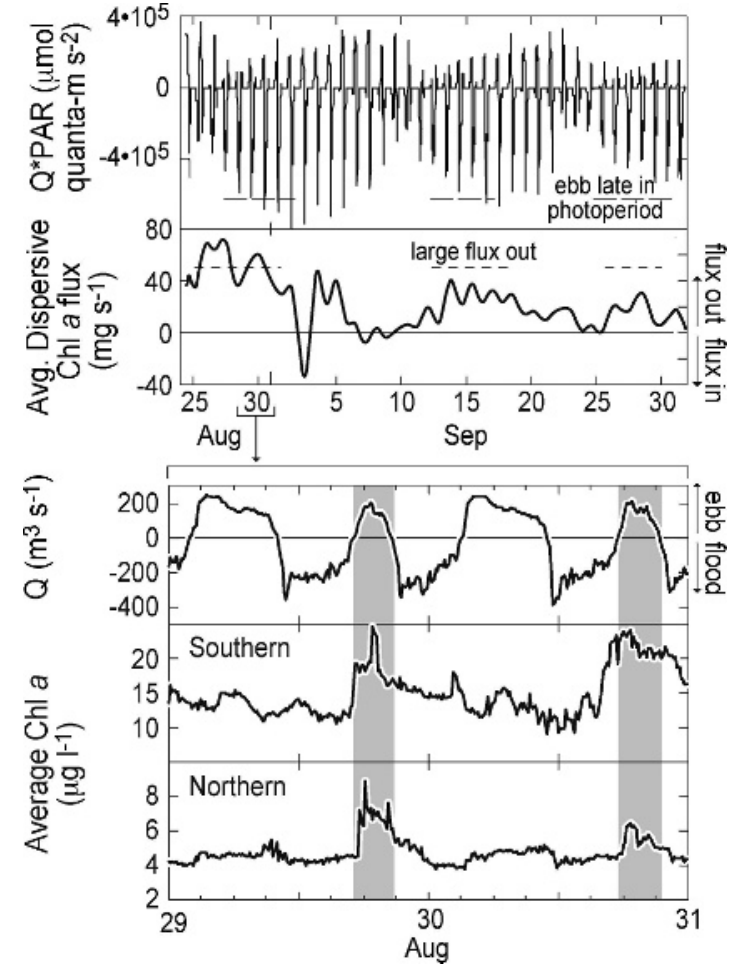

Fig. 10. The product of discharge (Q) and photosynthetically active radiation (PAR), and tidally averaged dispersive flux of chlorophyll $a$ (Lopez et al. 2006) at northern Mildred Island during late summer-early fall 2001; and discharge, depth-averaged chlorophyll $a$ in the south, and depth-averaged chlorophyll $a$ in the north during a period of high average dispersive flux (records for $\mathrm{Q}$ and northern chlorophyll $a$ are 2-d excerpts of longer time series shown in Lopez et al. 2006). Shaded periods highlight the coincidence of ebb with maximal southern chlorophyll $a$.

negative values correspond to daytime flood tides, and zero $\mathrm{Q} \times \mathrm{PAR}$ represents nighttime. Approximately every $2 \mathrm{wk}$ for a few days, positive $\mathrm{Q} \times \mathrm{PAR}$ occurs twice each day, meaning that two ebb tides squeeze into the photoperiod, one near the beginning and one near the end (e.g., August 27September 1, Fig. 10). The second daily spike in $Q$ $\times$ PAR represents an ebb occurring near the end of the photoperiod, or when southern chl $a$ is about maximal.

The tidally averaged dispersive flux of chl $a$ also varies over a fortnight (Fig. 10), with higher average flux corresponding to periods when positive $Q \times$ PAR occurs twice a day (i.e., when an ebb occurs late in the photoperiod). $\mathrm{Q}$, depth-averaged southern chl $a$, and depth-averaged northern chl $a$ are shown in Fig. 10 for a 2-d period with high average dispersive flux. Large flux events are the result of a large flow multiplied by a large concentration. During August 29-31, ebb coincided with the daily high in southern chl $a$, resulting in a large pulse in northern chl $a$ (Fig. 10). When ebbs coincided with 
daily periods of low southern chl $a$ (e.g., late night or early morning), northern chl $a$ generally did not rise significantly and dispersive flux was consequently reduced.

This fortnightly variation in dispersive chl $a$ flux is not due to well-known fortnightly cycles such as the spring-neap and tropic-equatorial cycles, which arise through the modulation of individual tidal components. The case at hand appears related to the modulation of a primarily semidiurnal physical process with an at least partially biological diurnal process. Because approximately $15 \mathrm{~d}$ elapses between successive identical phases for the combination of a semidiurnal signal and a diurnal signal, the alignment of ebb and maximum daily chl $a$ occurs only about every $2 \mathrm{wk}$, at those times maximizing the outward dispersive flux. The multiplication of a semidiurnal sinusoid (idealized Q) and a diurnal sinusoid with a mean (non-negative idealized chl $a$ ) reveals a 15-d low frequency beating in the combined signal (idealized $\mathrm{Q} \times \operatorname{chl} a$; not shown), similar to the approximately 2 -wk variation in our observed dispersive flux.

As in this case, we may expect to observe fortnightly variations of biological or chemical constituents in systems where important processes (e.g., photosynthesis, zooplankton grazing and migration, nutrient uptake) are diurnal and physical processes have a strong semidiurnal lunar tidal component (period of $12.4 \mathrm{~h}$; M2); such weekly scale variability could look spring-neap but would be due to physical-biological or physical-chemical interactions. Tides in the majority of the world's estuaries contain a significant semidiurnal component, so this phenomenon may be common. Another example was provided previously by Lucas and Cloern (2002), who demonstrated how fortnightly cycles in phytoplankton biomass may be regulated by interactions between semidiurnal shallowing and deepening of the water column, benthic grazers, and the photoperiod. We would not expect to find fortnightly constructive-destructive interference between physical and biological processes in regions where tides are diurnally dominant, such as portions of the Gulf of Mexico and Southeast Asia coast. Other processes varying over the 24-h period, such as wind-driven transport or thermal stratification, could produce a similar fortnightly periodicity through interaction with semidiurnal tidal transport.

Identification of underlying processes by techniques such as the scaling analysis above provides clues as to how cross-scale interactions may change if processes change. For southern chl $a$, scaling indicated that diurnal growth and wind-driven transport were critical in driving that diurnal variability. Since the approximately 2-wk modula- tion in dispersive chl $a$ export appears to arise from the interaction between a strong diurnal signal in the south and strong semidiurnal tidal advection, then as the diurnal processes become muted or eliminated towards winter (e.g., due to less intense light-driven growth or the transition from a summer diurnal wind pattern to a more event driven pattern), we would expect the fortnightly flux signal to weaken or disappear.

\section{Sample Bias Induced by High Frequency Variability}

Characterization of average or extreme values is a common objective of ecological and regulatory monitoring programs. For example, ecotoxicologists may be interested in long-term average exposure of organisms to food or contaminants; regulators may be concerned with maximum salinity or minimum dissolved oxygen. Whether one is interested in averages (DiLorenzo et al. 2004) or extremes, temporally coarse sampling of a periodic signal could provide misleading or incorrect information if high frequency variability exists in the measured constituent. This phenomenon is known as aliasing and is well documented in the time series literature (Hamming 1977; Stearns and David 1988). These and other basic time series texts clearly show that high frequency aliasing can cause spurious long-term trends in cases where the shortterm variability (in our case hourly time scale) is on the order of the real longer term trend. Although they may not be feasible in the long term, high frequency measurements obtained for a short period of time can aid in the design of more temporally coarse sampling schemes and guide interpretation of discrete measurements.

Systematic subsampling of chl $a$ at the northern station (where subsampling of the original time series was performed daily at $6 \mathrm{am}$, noon, and $6 \mathrm{pm}$ ) reveals errors that can arise when the amplitude of variability of the sampled quantity is large (Fig. 11). In this case, we see that the magnitude of dayaveraged chl $a$ is generally captured well by the 6 am and noon daily sampling but less well by the $6 \mathrm{pm}$ sampling scheme. (Day-averaged chl $a$ is calculated from midnight to midnight and is very similar to tidally filtered chl a.) All subsampling schemes introduce structure (e.g., peaks and valleys) not evident in the day-averaged time series, with largest deviations corresponding to the $6 \mathrm{pm}$ sampling scheme. During August 24-31, the 6 pm sampling scheme suggests the development and demise of a multiday phytoplankton bloom, while the dayaveraged time series indicates a relatively steady, slow decline over that period. Subsampling of the first portion of this time period (August 24-28) also shows how the sign of change (increase versus decrease) in the sub-sampled constituent can be 


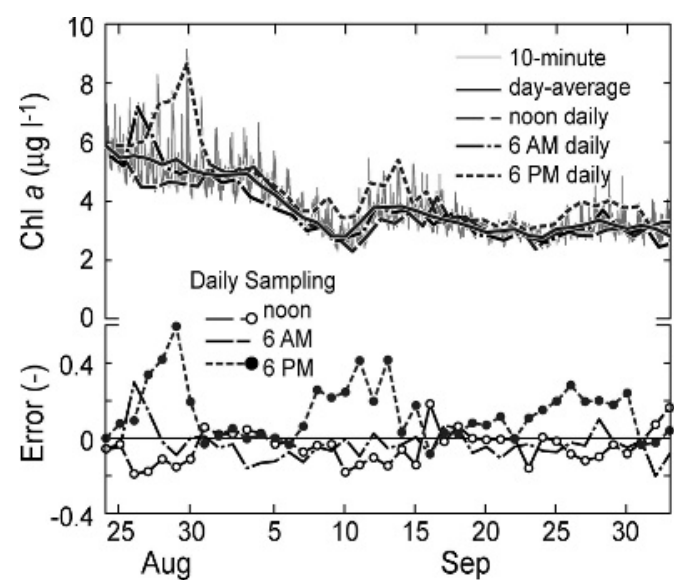

Fig. 11. Three chlorophyll $a$ subsampling schemes (daily sampling at noon, $6 \mathrm{am}$, and $6 \mathrm{pm}$ ) compared with day-averaged chlorophyll $a$ and the original 10-min time series from northern Mildred Island, and error for each subsampling scheme, calculated relative to the day average.

incorrect relative to the mean. Comparison of the 6 am and $6 \mathrm{pm}$ sampling schemes further shows how measured peak concentrations can be offset by several days depending on the time of daily sampling.

In Fig. 11, we quantify the error of subsampling relative to the day-average; error associated with 6 pm sampling reaches as high as $60 \%$. Deviations from the day-averaged signal in the $6 \mathrm{pm}$ sampling strategy are greatest when the short time scale variability becomes large due to the coincidence of ebbs with the end of the photoperiod every $2 \mathrm{wk}$. Errors associated with 6 am and noon sampling in Fig. 11 are seldom more than $20 \%$, suggesting that for this constituent at this location morning or midday sampling, or a tidally based scheme avoiding high-water or low-water sampling, would generally capture the average well. If maximum chl $a$ were the sampling goal, low water sampling would be optimal; if minimum chl $a$ were desired, high water sampling would be optimal.

The time series examined in this paper show that different cosampled constituents may vary over different periods and that the periodicity of a single constituent may vary in time or over short distances, further complicating the design of a lower resolution sampling program. Short-duration high frequency sampling of water quality, coupled with a subsampling exercise like that shown in Fig. 11, can identify whether large amplitude, high frequency variability in measured constituents exists; determine optimal sampling times relative to time of day, tidal phase, or other relevant period; allow for the estimation of error associated with the chosen sampling scheme; and help balance monitoring goals and errors incurred when more than one period of variability is involved.

Understanding of the mechanisms behind high frequency scalar variability, such as that presented above using scaling, can guide shifts in sampling design as processes change (e.g., seasonally). The strong diurnal variability in scalars in southern MI was surprising to us since the Delta overall is a strongly tidal setting. Now that we are aware of the strong biological and wind-driven pattern of summer-fall variability, we would recommend that any discrete sampling scheme during that season be diurnally based. As those drivers become muted or eliminated toward winter, we might expect a more semidiurnal variation in $\operatorname{chl} a$ and shift to a tidally based sampling scheme. In this way, process understanding helps us anticipate system changes and adapt our own interactions with the system.

\section{Summary}

High frequency measurements in a semi-enclosed tidal habitat revealed that large amplitude intradaily periodicity in water quality can vary between water quality constituents, across short distances within a habitat, and over time. In nature, and especially in physically dynamic systems, multiple physical, chemical, or biological processes may simultaneously act on a given water quality constituent, and each such process will have its own characteristic period and amplitude of variability. Intradaily variations in water quality are expected in other surface water environments where periodic physical forcings such as tides or diurnal wind operate in the presence of scalar gradients or where other natural periodic processes such as diurnal heating, photosynthesis, or nutrient uptake occur.

The scaling approach developed herein provides one way to explain the observed periodicities. The relationships in Table 1 could be directly applied for similar analysis in other environments, or they could be modified to describe the effect of other processes on other constituents (see Appendix). The three scalars studied here could be taken as surrogates for other constituents that undergo similar physical, chemical, or biological influences, or that are affected by SC, T, or chl $a$, but which are more difficult to measure.

Meaningful environmental and ecological monitoring provides one reason for measuring and understanding high frequency variability in transported quantities. Detailed knowledge of intradaily variability in water quality may not be the goal of all scientists, managers, and regulators, but an awareness of the existence and nature of that variability may be critical to the appropriate design of temporally coarser monitoring programs and interpretation of low frequency data. Without knowledge of the 
amplitude and frequency of variability for a constituent of concern, infrequent sampling may incorrectly characterize maxima, minima, mean values, and long-term trends. Short-duration high frequency sampling can reveal the period and amplitude of intradaily fluctuations in water quality and aid the design of coarser sampling schemes, interpretation of those measurements, and assessment of error. Understanding of the underlying process can help us anticipate changes in scalar variability and adapt our sampling program accordingly.

The key to prediction and understanding of ecosystems lies in the elucidation of mechanisms underlying observed patterns (Levin 1992). We have shown how high frequency interactions may drive observed long-term trends and time-averaged quantities. The phasing between the semidiurnal tidal current and diurnally varying phytoplankton biomass in the southern source region can govern weekly scale variations in the dispersive export of biomass from northern MI. This kind of mechanistic understanding can help us predict responses of this or similar habitats to natural and anthropogenic change. Other high frequency interactions with low frequency consequences are expected in systems where some quantity of interest (e.g., phytoplankton biomass) is a function of a process (e.g., lightlimited growth) that depends nonlinearly on a periodic variable (e.g., water column height, tidal velocity, or turbulent mixing coefficient). Given the complex combinations of processes operating in the Earth's surface water systems, many more such connections "between domains of scale" (Wiens 1989 , p. 394) must exist. Without adequately resolved data, whether sampled in nature or generated by numerical models, we will never be capable of identifying those connections. Without an understanding of those connections, our ability to anticipate and appropriately respond to ecosystem changes, such as the collapse of valued aquatic populations, will be severely limited.

\section{ACKNOWLEDGMENTS}

We are grateful to Jim Cloern for fundamental ideas and discussions leading to the development of this manuscript. Thanks also to Jan Thompson, Robin Stewart, Sam Luoma, and two anonymous reviewers for their helpful comments. A battalion of samplers was instrumental in obtaining the data discussed: Kurt Battenfield, Jay Cuetara, Jim DeRose, Jim George, Cathy Ruhl, Mike Simpson, Jon Yokomizo (U.S. Geological Survey California Water Science Center, Sacramento, California); Andy Arnsberg, Jim Cloern, Linda Cloern, Elizabeth Elias, Bob Herzog, Nancy Monsen, Francis Parchaso, Heather Peterson, Byron Richards, Michelle Shouse, Bill Sobczak, Jan Thompson (USGS National Research Program, Menlo Park, California); Kris May (Stanford University); and Lloyd Brenn, Mike Dempsey, Steve Hayes, Eric Santos, Kitty Triboli, Scott Waller (California Department of Water Resources, Environmental Services Office, Sacramento, California). Thanks to Martina Doblin, Greg Cutter, Lynda
Cutter, and Stephen Baines for their discrete measurements of chlorophyll and POC, Brian Cole for his phytoplankton productivity measurements, Amy Little for her zooplankton grazing estimates, and Cathy Ruhl for her assistance with interpreting flow rating information. We appreciate helpful discussions with Alan Jassby, Wim Kimmerer, Jeff Gartner, and Ralph Cheng, and Jeanne Dileo's illustrative brilliance. This work was supported by the CALFED San Francisco Bay-Delta Ecosystem Restoration and Science Programs (Contracts \#4600001955, \#01AA2000103) and the USGS National Research Program.

\section{Literature Cited}

Baines, S. B., N. S. Fischer, M. A. Doblin, G. A. Cutter, ANd L. S. CUTTER. 2004. Light dependence of selenium uptake by phytoplankton and implications for predicting selenium incorporation into food webs. Limnology and Oceanography 49:566578.

Bennett, A. W. And P. B. Moyle. 1996. Where have all the fishes gone? Interactive factors producing fish declines in the Sacramento-San Joaquin Estuary, p. 519-542. In J. T. Hollibaugh (ed.), San Francisco Bay: The Ecosystem. Pacific Division of the American Association for the Advancement of Science, San Francisco, California.

CALFED. 2000. California's Water Future: A Framework for Action. CALFED Bay-Delta Program, Sacramento, California.

California Bay-Delta Authority. 2004. CALFED Bay-Delta Program Ecosystem Restoration Multi-Year Program Plan (Years 5-8). California Bay-Delta Authority, Sacramento, California.

Dilorenzo, J. L., R. J. Filadelfo, C. R. Surak, H. S. Litwack, V. K. Gunawardana, AND T. O. Najarian. 2004. Tidal variability in the water quality of an urbanized estuary. Estuaries 27:851-860.

FisCHer, H. B. 1976. Mixing and dispersion in estuaries. Annual Review of Fluid Mechanics 8:107-133.

Fischer, H. B., E. J. List, R. C. Y. KoH, J. Imberger, AND N. H. BROOKS. 1979. Mixing in Inland and Coastal Waters, 1st edition. Academic Press, Inc., San Diego, California.

Foreman, M. G. G. 1977. Manual for Tidal Heights Analysis and Prediction. Institute of Ocean Sciences, PMS Report 77-10. Patricia Bay, Sidney, British Columbia.

GeYeR, W. R. AND H. NePf. 1996. Tidal pumping of salt in a moderately stratified estuary. Coastal and Estuarine Studies 53: 213-226.

Hamming, R. W. 1977. Digital Filters, 2nd edition. Prentice-Hall, Englewood Cliffs, New Jersey.

Hubertz, E. D. AND L. B. CAhoon. 1999. Short-term variability of water quality parameters in two shallow estuaries of North Carolina. Estuaries 22:814-823.

Jacobs, K. L., S. N. LuOMA, AND K. A. TAYLOR. 2003. CALFED: An experiment in science and decision making. Environment 45:3041.

Jassby, A. D., J. E. Cloern, AND B. E. Cole. 2002. Annual primary production: Patterns and mechanisms of change in a nutrientrich tidal ecosystem. Limnology and Oceanography 47:698-712.

Jay, D. A., R. J. Uncles, J. L. Largier, W. R. Geyer, J. Vallino, AND W. R. Boynton. 1997. A review of recent developments in estuarine scalar flux estimation. Estuaries 20:262-280.

Kaplan, D. M., J. L. Largier, S. Navarrete, R. Guinez, and J. C. CASTILLA. 2003. Large diurnal temperature fluctuations in the nearshore water column. Estuarine Coastal and Shelf Science 57: 385-398.

KimmereR, W. J. AND J. J. ORSI. 1996. Changes in the zooplankton of the San Francisco Bay Estuary since the introduction of the clam Potamocorbula amurensis, p. 403-424. In J. T. Hollibaugh (ed.), San Francisco Bay: The Ecosystem. Pacific Division of the American Association for the Advancement of Science, San Francisco, California. 
Lacy, J. R., M. T. Stacey, J. R. Burau, and S. G. Monismith. 2003. The interaction of lateral baroclinic forcing and turbulence in an estuary. Journal of Geophysical Research 108:C3.

LEVIN, S. A. 1992. The problem of pattern and scale in ecology. Ecology 73:1943-1967.

Lopez, C. B., J. E. Cloern, T. S. Schraga, A. J. Little, L. V. Lucas, J. K. Thompson, AND J. R. Burau. 2006. Ecological values of shallow-water habitats: Implications for restoration of disturbed ecosystems. Ecosystems 9:422-440.

LuCAS, L. V. AND J. E. CloERn. 2002. Effects of tidal shallowing and deepening on phytoplankton production dynamics: A modeling study. Estuaries 25:497-507.

Lucas, L. V., J. E. Cloern, J. K. Thompson, and N. E. Monsen. 2002. Functional variability of habitats within the SacramentoSan Joaquin Delta: Restoration implications. Ecological Applications 12:1528-1547.

Lucas, L. V., J. R. Koseff, J. E. Cloern, S. G. Monismith, and J. K. ThOMPSON. 1999a. Processes governing phytoplankton blooms in estuaries. I: The local production-loss balance. Marine Ecology Progress Series 187:1-15.

Lucas, L. V., J. R. Koseff, S. G. Monismith, J. E. Cloern, And J. K. Thompson. 1999b. Processes governing phytoplankton blooms in estuaries. II: The role of horizontal transport. Marine Ecology Progress Series 187:17-30.

Miyamoto, K., Y. Ado, Y. Asada, J. R. Benemann, M. Kishimoto, J. MiYAKE, AND N. Nishio. 1997. Renewable biological systems for alternative sustainable energy production. Food and Agriculture Organization of the United Nations, FAO Agricultural Services Bulletin No. 128. Rome, Italy.

Monsen, N. E., J. E. Cloern, And L. V. LuCAs. 2002. A comment on the use of flushing time, residence time, and age as transport time scales. Limnology and Oceanography 47:1545-1553.

Mount, J. AND R. Twiss. 2005. Subsidence, sea level rise, and seismicity in the Sacramento-San Joaquin Delta. San Francisco Estuary and Watershed Science 3:Article 5.

Muller-Solger, A. B., A. D. Jassby, AND C. D. Muller-Navarra. 2003. Nutritional quality of food resources for zooplankton (Daphnia) in a tidal freshwater system (Sacramento-San Joaquin River delta). Limnology and Oceanography 45:1468-1476.

PARchevsky, K. V. 2000. Using regularizing algorithms for the reconstruction of growth rate from the experimental data. Ecological Modelling 133:107-115.

Parchevsky, K. V. And V. P. Parchevsky. 2001a. Reconstruction of instantaneous rate from experimental data by means of Tikhonov regularization. Ecologiya Morya 55:87-91.

Parchevsky, V. P. AND K. V. PARChevsky. 2001b. Modelling of reconstruction of instantaneous rate from data with different variability using Tikhonov regularization. Ecologiya Morya 55:9296.

Parsons, T. R., Y. Maita, And C. M. LALli. 1984. A Manual of Chemical and Biological Methods for Seawater Analysis, 1st edition. Pergamon Press, Oxford, U.K.

Ruhl, C. A. AND M. R. Simpson. 2005. Computation of streamflow in tidally affected areas using the index velocity method. United States Geological Survey, Scientific Investigations Report No. 2005-5004. Sacramento, California.

SAnderson, P. G. AND D. M. TAYLOR. 2003. Short-term water quality variability in two tropical estuaries, central Sumatra. Estuaries 26:156-165.

SHANAHAN, P. 1985. Water temperature modeling: A practical guide. In Proceedings of stormwater and water quality model users group meeting. United States Environmental Protection Agency, Environmental Research Laboratory, EPA-600/9-85003. Athens, Georgia.

Sobczak, W. V., J. E. Cloern, A. D. Jassby, B. E. Cole, T. S. Schraga, And A. Arnsberg. 2005. Detritus fuels ecosystem metabolism but not metazoan food webs in San Francisco Estuary's freshwater delta. Estuaries 28:124-137.

Sobczak, W. V., J. E. Cloern, A. D. Jassby, And A. B. MullerSOLGER. 2002. Bioavailability of organic matter in a highly disturbed estuary: The role of detrital and algal resources. Proceedings of the National Academy of Sciences 99:8101-8105.

STEARnS, S. D. AND R. A. DAVID. 1988. Signal Processing Algorithms. Prentice Hall, Eaglewood Cliffs, New Jersey.

Stommel, H. AND H. G. FARMER. 1952. On the nature of estuarine circulation. Woods Hole Oceanographic Institution, Technical Report No. 52-88. Woods Hole, Massachusetts.

TAYlor, A. H. AND J. A. STEPhens. 1993. Diurnal variations of convective mixing and the spring bloom of phytoplankton. Deep-Sea Research II 40:389-408.

TAYLOR, C. D. AND B. L. HowEs. 1994. Effect of sampling frequency on measurements of seasonal primary production and oxygen status in near-shore coastal ecosystems. Marine Ecology Progress Series 108:193-203.

Thomann, R. V. And J. A. Mueller. 1987. Principles of Surface Water Quality Modeling and Control. Harper and Row, Publishers, Inc., New York.

VAulot, D. AND D. Marie. 1999. Diel variability of photosynthetic picoplankton in the equatorial Pacific. Journal of Geophysical Research 104:3297-3310.

Walters, R. A. AND C. Heston. 1982. Removing tidal-period variations from time-series data using low-pass digital filters. Journal of Physical Oceanography 12:112-115.

WiEns, J. A. 1989. Spatial scaling in ecology. Functional Ecology 3: 385-397.

\section{SOURCES OF UNPUBLISHED MATERIALS}

BaInes, S. G. unpublished data. Marine Sciences Research Center, Stony Brook University, Stony Brook, New York 11794-5000.

Burau, J. R. unpublished data. United States Geological Survey, Placer Hall, 6000 J Street, Sacramento, California 95819-6129.

California Department of Water Resources California Data Exchange Center (CDEC). Public communication. http:// cdec.water.ca.gov

CALIFORnia IrRigation MANAgEment Information System (CIMIS). Public communication. http://www.cimis.water.ca.gov

Cole, B. E. personal communication. United States Geological Survey, 345 Middlefield Road, MS \#150, Menlo Park, California 94025 .

Cuetara, J. unpublished data. Solano County Water Agency, 6040 Vaca Station Road, Building 84, Elmira, California 95625.

Cutter, G. unpublished data. Department of Ocean, Earth, and Atmospheric Sciences, Old Dominion University, 4600 Elkhorn Ave., Norfolk, Virginia 23529-0276.

CutTer, L. unpublished data. Department of Ocean, Earth, and Atmospheric Sciences, Old Dominion University, 4600 Elkhorn Ave., Norfolk, Virginia 23529-0276.

Doblin, M. A. unpublished data. Institute for Water and Environmental Resource Management, Department of Environmental Sciences, University of Technology, Sydney, P. O. Box 123 Broadway, NSW 2007 Australia.

FrAM, J. unpublished data. Marine Science Institute, University of California, Santa Barbara, Santa Barbara, California 931066150 .

LitTle, A. J. personal communication. California Department of Health Services, 50 D Street, Room 200, Santa Rosa, California 95404.

MARTIN, M. unpublished data. 631 Davis Hall \#1710, University of California, Berkeley, Berkeley, California 94720-1710.

NATIONAL OCEANIC AND ATMOSPHERIC AdMinistration (NOAA). Public communication. http://www.aeroclubedetatui.com.br/ sunsetcalc/tsunsetcalc.htm

RuHL, C. A. unpublished data. United States Geological Survey, California Water Science Center, Placer Hall, $6000 \mathrm{~J}$ Street, Sacramento, California 95819-6129.

StACEY, M. T. unpublished data. University of California, Berkeley, 665 Davis Hall, Berkeley, California 94720-1710. 
Thompson, J. K. unpublished data. United States Geological Survey, 345 Middlefield Road, MS \#496, Menlo Park, California 94025 .

Received, September 19, 2005 Accepted, April 11, 2006

\section{Appendix}

This appendix provides details relevant to the derivation and calculation of scalar oscillation magnitudes associated with horizontal advection, vertical mixing, atmospheric heating, evaporation, phytoplankton growth, and zooplankton grazing. See Table 1 for Equations A-G and Table 2 for relevant parameter values and definitions.

\section{Horizontal ADVEction}

For use in Eq. A-B, oscillation amplitudes for streamwise and transverse velocity ( $\hat{u}$ and $\hat{v}$, respectively) and the primary period ( $\tau$ for each location and direction were identified with harmonic analysis of the entire velocity time series (Foreman 1977). $\partial \mathrm{C} / \partial \mathrm{x}$ and $\partial \mathrm{C} / \partial \mathrm{y}$ are the average horizontal scalar gradient magnitudes estimated along principle flow directions from interpolated spatial maps of SC, T, and chl $a$ based on five sampling circuits that occurred on 5-6 September 2001 (see Fig. 8 for sample maps). For northern MI, gradients along channels were also used. Because flow at the northern site was largely bidirectional, due to that station's location at a narrow levee opening, only the streamwise advection scale was calculated there (Eq. A). At the southern site, flow was less confined and demonstrated potentially important features in both streamwise and tranverse directions. Therefore, at that location $\Delta \mathrm{C}_{\mathrm{adv}-\mathrm{x}}$ (streamwise, Eq. A) and $\Delta \mathrm{C}_{\text {adv-y }}$ (transverse, Eq. B) were both calculated. In the south, two periods contributed significantly to variability in $\mathrm{u}$, so Eq. A was applied separately for each period.

\section{Vertical Mixing}

To derive the scaling expression for $\Delta \mathrm{C}$ associated with vertical mixing (Eq. C), we discretize term III in Eq. 1 as the diffusive flux at the water surface (which is zero) minus the diffusive flux at the midpoint between upper and lower sensors divided by $\Delta \mathrm{z}$, the distance between that midpoint and the water surface (see Fig. 3). This results in the approximation $\partial \mathrm{C} / \partial \mathrm{t} \approx-\left(\mathrm{K}_{\mathrm{z}} / \Delta \mathrm{z}\right) \partial \mathrm{C} / \partial \mathrm{z} . \partial \mathrm{C} / \partial \mathrm{z}$ is the vertical scalar gradient, which is assumed constant and taken as the median gradient magnitude calculated from the difference between upper and lower sensor measurements over the entire scalar time series. $\mathrm{K}_{\mathrm{z}}$ for both current shear and wind was estimated as $0.067 \mathrm{u}_{*} \overline{\mathrm{h}}\left(1+3.33 \mathrm{Ri}_{\mathrm{g}}\right)^{-3 / 2}$, combining the depth-averaged estimate for an unstratified unidirectional flow with the gradient
Richardson number $\left(\mathrm{Ri}_{\mathrm{g}}\right)$ based Munk-Anderson modification for the damping effect of stratification (Fischer et al. 1979). $\overline{\mathrm{h}}$ is the temporally averaged water column depth. We used the median $\mathrm{Ri}_{\mathrm{g}}$ (defined as $\left.\operatorname{Ri}_{\mathrm{g}}=\mathrm{g}(\partial \rho / \partial \mathrm{z}) / \rho_{\mathrm{o}}(\partial \overrightarrow{\mathbf{U}} / \partial \mathrm{z})^{2}\right)$ over the study period, calculating the vertical water density gradient $\partial \rho / \partial z$ from the difference in density at the two sensor heights and the vertical velocity shear $\partial \overrightarrow{\mathbf{U}} / \partial \mathrm{z}$ from the difference in velocity between top and bottom bins; $\mathrm{g}$ is gravitational acceleration and $\rho_{\mathrm{o}}$ is a reference density for water.

Calculation of $u_{*}$ is the main difference between the calculations of $\Delta \mathrm{C}$ for current shear and wind induced mixing. For current shear, $\mathrm{u}_{* \mathrm{cs}}=|\overrightarrow{\mathrm{U}}| /\left(10+1 / \kappa+(2.3 / \kappa) \log _{10}\left[\mathrm{z}_{\mathrm{up}} / \overline{\mathrm{h}}\right]\right)$, which employs the assumption that $\mathrm{u}_{* \mathrm{cs}}$ is $10 \%$ of the depth-averaged velocity and that the velocity profile follows that of a wide two-dimensional channel (Fischer et al. 1979). $\kappa$ is 0.4, $|\overrightarrow{\mathrm{U}}|$ is the current speed in the uppermost bin, and $z_{\text {up }}$ is the height of the uppermost bin (see Fig. 3). For wind, $\mathrm{u}_{* \text { wind }}=\left(\mathrm{C}_{\mathrm{D}} \rho_{\mathrm{a}} \mathrm{U}^{2}{ }_{\text {wind }} / \rho_{\mathrm{o}}\right)^{1 / 2}$, where $\mathrm{C}_{\mathrm{D}}$ is the drag coefficient and $\rho_{\mathrm{a}}$ is the density of air (Fischer et al. 1979). For both wind and current shear, $\hat{\mathrm{u}}_{*}$ and $\tau$ were identified with harmonic analysis of the calculated $\mathrm{u}_{*}$ time series. At the southern station, two periods contributed to variability in $\mathrm{u}_{* \mathrm{cs}}$, so Eq. C was applied separately for both periods.

\section{Atmospheric Heating}

Our scaling estimate for $\Delta \mathrm{T}_{\text {heat }}$ (Eq. D) is based on the expression $\partial \mathrm{T} / \partial \mathrm{t} \sim \Delta \mathrm{H} /\left(\rho_{\mathrm{o}} \mathrm{c}_{\mathrm{p}} \mathrm{h}\right)$, where $\mathrm{c}_{\mathrm{p}}$ is the specific heat of water (Thomann and Mueller 1987). We found the amplitude $(\Delta \hat{\mathrm{H}})$ and period of oscillation with harmonic analysis.

The northern station was located in a deep localized hole, and water temperature measured at that strongly advective location is expected to represent heating that occurred at other locations within a tidal excursion distance. In calculating $\Delta \mathrm{T}_{\text {heat }}$ (Eq. D), we therefore substituted for local mean depth a value representing the average water column depth a Lagrangian water parcel passing through the site would see over time. This value $(7 \mathrm{~m})$ is based on depths in the surrounding channels and within northern MI. Because the bathymetry in the south is relatively uniform, the local mean depth there was used for this calculation.

\section{EVAPORATION}

The scaling expression for $\Delta \mathrm{SC}_{\text {evap }}$ (Eq. E) is based on a simple mass balance that assumes 1) SC $=\mathrm{SC}_{\mathrm{o}} \mathrm{h}_{\mathrm{o}} / \mathrm{h}$, where $\mathrm{SC}_{\mathrm{o}}$ and $\mathrm{h}_{\mathrm{o}}$ are initial values (held constant) so that instantaneous SC is linearly 
and inversely related to instantaneous water height $\mathrm{h}$; and 2) $\partial \mathrm{h} / \partial \mathrm{t}=-\mathrm{E}_{\mathrm{v}}$, the evaporation rate. Differentiating the above expression for SC with respect to $\mathrm{t}$, substituting $-\mathrm{E}_{\mathrm{v}}=\hat{\mathrm{E}}_{\mathrm{v}} \sin (2 \Pi \mathrm{t} / 24)$ for $\partial \mathrm{h} / \partial \mathrm{t}$ (thus producing an expression analogous to terms I and $\mathrm{V}$ in Eq. 1), and integrating over one half cycle produces the scaling expression in Eq. E. We take $\mathrm{SC}_{\mathrm{o}}$ and $\mathrm{h}_{\mathrm{o}}$ to be mean values (as for heat flux, we assume $\overline{\mathrm{h}}$ at the northern station is $7 \mathrm{~m}$, the Lagrangian estimate). Harmonic analysis performed on the $\mathrm{E}_{\mathrm{v}}$ time series identified $\hat{\mathrm{E}}_{\mathrm{v}}$ and $\tau$. Calculation of $\mathrm{E}_{\mathrm{v}}$ followed the approach of Thomann and Mueller (1987).

\section{GROWTH AND GRAZING}

A zero-dimensional model of local depth-averaged phytoplankton dynamics in a tidal water column was used to calculate $\mu$, the phytoplankton net specific growth rate (Lucas and Cloern 2002). For the north, $\overline{\mathrm{h}}$ was assumed to be the Lagrangian estimate $(7 \mathrm{~m})$. The scaling expression for $\Delta \mathrm{Chl}_{\text {growth }}$ (Eq. F) uses $\mathrm{Chl}_{\mathrm{o}}$ (an initial value held constant and taken to be a mean value), $\hat{\mu}$ (the amplitude of oscillation of $\mu$, taken as one half the difference between daily $\mu_{\max }$ and $\left.\mu_{\min }\right)$, and $\tau$ (taken as $24.0 \mathrm{~h}$ ).
The following quantities were specified for calculation of $\mu$, based on measurements taken at or near MI on or near 5-6 September 2001: total daily surface PAR (52 mol quanta $\mathrm{m}^{-2} \mathrm{~d}^{-1}$ ); daylength (12.9 h; National Oceanic and Atmospheric Administration public communication); light attenuation coefficient $\left(1.5 \mathrm{~m}^{-1}\right.$ for the north; $2.1 \mathrm{~m}^{-1}$ for the south from measured irradiance profiles); average $\mathrm{T}$ of $24^{\circ} \mathrm{C} ; \mathrm{P}_{\max }$ (maximum photosynthetic rate; $3.5 \mathrm{mg} \mathrm{C} \mathrm{mg}$ chl $a^{-1} \mathrm{~h}^{-1}$; Cole personal communication; Baines et al. 2004); a (photosynthetic efficiency at low irradiance; 0.02 ( $\mathrm{mg} \mathrm{C} \mathrm{mg}$ chl $a^{-1} \mathrm{~h}^{-1}$ ) ( $\mu$ mol quanta $\left.\mathrm{m}^{-2} \mathrm{~s}^{-1}\right)^{-1}$; Cole personal communication); and tidal range $(1 \mathrm{~m})$.

Specific zooplankton grazing rates $\left(\mu_{\mathrm{zp}}\right)$ were estimated based on zooplankton sampling performed on 5-6 September 2001 (Little personal communication; Lopez et al. 2006). $\hat{\mu}_{\mathrm{zp}}$ (used in Eq. G) was estimated from a sinusoidal fit to five estimated grazing rates for southern MI over a 30hour period. Eq. F could be modified for estimating the effect of biotic uptake on fluctuations in nutrient or contaminant concentrations, by substituting the relevant concentration for chl $a$ and the amplitude of an oscillating uptake rate for $\hat{\mu}$. 